UNIVERSIDADE DE BRASÍLIA

FACULDADE DE TECNOLOGIA

DEPARTAMENTO DE ENGENHARIA ELÉTRICA

\title{
ANÁLISE DE ESTABILIDADE TRANSITÓRIA EM SISTEMAS ELÉTRICOS DE POTÊNCIA
}

FÁBIO FERREIRA GOMES DIAS FERNANDO CARDOSO PILONI

ORIENTADOR: FRANCISCO DAMASCENO FREITAS

MONOGRAFIA DE GRADUAÇÃO EM ENGENHARIA ELÉTRICA 
UNIVERSIDADE DE BRASÍLIA

FACULDADE DE TECNOLOGIA

DEPARTAMENTO DE ENGENHARIA ELÉTRICA

\section{ANÁLISE DE ESTABILIDADE TRANSITÓRIA EM SISTEMAS ELÉTRICOS DE POTÊNCIA}

\section{FÁBIO FERREIRA GOMES DIAS FERNANDO CARDOSO PILONI}

MONOGRAFIA DE GRADUAÇÃO SUBMETIDA AO DEPARTAMENTO DE ENGENHARIA ELÉTRICA DA FACULDADE DE TECNOLOGIA DA UNIVERSIDADE DE BRASÍLIA, COMO PARTE DOS REQUISITOS NECESSÁRIOS PARA A OBTENÇÃO DO GRAU DE ENGENHEIRO ELETRICISTA.

APROVADA POR:

Prof. Francisco Damasceno Freitas, Dr. (ENE-UnB)

(Orientador)

Prof. Luis Filomeno de Jesus Fernandes, Dr. (FGA-UnB)

(Examinador Interno)

Eng. Vítor Nunes Nishiyama, (ELETRONORTE)

(Examinador Externo)

BRASÍLIA/DF, 08 DE SETEMBRO - 2010. 
FICHA CATALOGRÁFICA

DIAS, FÁBIO FERREIRA GOMES \& PILONI, FERNANDO CARDOSO

ANÁLISE DE ESTABILIDADE TRANSITÓRIA EM SISTEMAS ELÉTRICOS

DE POTÊNCIA. [Distrito Federal] 2010.

xiii, 105p., 297 mm (ENE/FT/UnB, Engenheiro, Engenharia Elétrica,2010)

Monografia de Graduação - Universidade de Brasília.

Faculdade de Tecnologia - Departamento de Engenharia Elétrica.

1. Estabilidade transitória

2. Sistema de potência

3. Oscilações eletromecânicas

4. Integração Numérica

I. $\mathrm{ENE} / \mathrm{FT} / \mathrm{UnB}$

II. Título (série)

\section{REFERÊNCIA BIBLIOGRÁFICA}

Dias, F. F. G. e Piloni, F. C. (2010). Análise de Estabilidade Transitória em Sistemas Elétricos de Potência, Publicação ENE.TG 2010, Departamento de Engenharia Elétrica, Universidade de Brasília, Brasília, DF, 63p.

\section{CESSÃO DE DIREITOS}

NOME DOS AUTORES: Fábio F. G. Dias \& Fernando Cardoso Piloni.

TÍTUlO DA MONOGRAFIA DE GRADUAÇÃO: Análise de estabilidade transitória em sistemas elétricos de potência

GRAU / ANO: Engenheiro eletricista / 2010

É concedida à Universidade de Brasília permissão para reproduzir cópias desta monografia de graduação e para emprestar ou vender tais cópias somente para propósitos acadêmicos e científicos. O autor reserva outros direitos de publicação e nenhuma parte desta dissertação de graduação pode ser reproduzida sem a autorização por escrito do autor. 


\section{RESUMO}

O presente trabalho tem por objetivo descrever uma metodologia para calcular e apresentar resultados para a análise de estabilidade transitória em sistemas elétricos de potência. Para esta finalidade, foi utilizado o software Matlabß). A resolução das equações diferenciais e algébricas para representar o problema foram realizadas numericamente. Com este objetivo, foram avaliados métodos numéricos usuais, como o de Euler, de Runge-Kutta e o trapezoidal. Para a entrada e a saída de dados foi desenvolvida uma interface gráfica que mostra o diagrama unifilar do sistema e as opções para o usuário entrar com os dados de interesse. Também é mostrada a saída gráfica relativa à simulação. Para avaliar o desempenho da metodologia de cálculo de transitórios eletromecânicos e da interface de entrada/saída de dados, simulações foram feitas em dois sistemas de testes: um com 3 barras e outro com 9 .

Palavras-chave . Sistema de potência, Estabilidade transitória, Oscilações eletromecânicas, Integração Numérica 


\section{DEDICATÓRIA}

À minha família, amigos e professores. Aos meus avós, Cecilio e Vilma, por serem meu exemplo de vida.

Fábio Ferreira Gomes Dias

Fernando Cardoso Piloni 


\section{AGRADECIMENTO}

Aos meus pais Giovanne e Ivone, por todos os sacrificios que tiveram que fazer para que eu me tornasse a pessoa que sou hoje.

Aos meus professores e educadores aos quais devo tudo que aprendi ao longo dos anos. Em especial ao professor Francisco Damasceno Freitas pela atenção e paciência na condução deste trabalho.

Aos meus amigos irmãos que sempre estiveram por perto mesmo nas maiores dificuldades.

A todos os meus familiares, por me incentivar a continuar e atingir este objetivo.

Fábio Ferreira Gomes Dias

Aos meus pais e a todos que eu chamo de familia por serem as pessoas que amo e nas quais confio.

À Grazy e à Lorena, por serem as mulheres da minha vida.

Em especial, a "familia"tia Vera, por ter me proporcionado inúmeras oportunidades.

Fernando Cardoso Piloni 


\section{Sumário}

1 INTRODUÇÃO GERAL 1

1.1 Contextualização . . . . . . . . . . . . . . . . 1

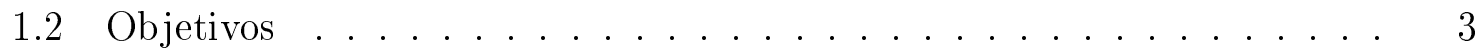

1.3 Organização do trabalho . . . . . . . . . . . . . . 3

2 ANÁLISE DE ESTABILIDADE EM SISTEMAS ELÉTRICOS DE POTÊNCIA

2.1 FORMUlaÇÃO GERAL DO PROBLEMA . . . . . . . . . . . 4

2.2 CRITÉRIO DAS ÁREAS IGUAIS . . . . . . . . . . . . 6

2.2.1 Critério das Áreas Iguais para Sistema Máquina-Barra Infinita . 8

2.3 MÉTODOS DE INTEGRAÇÃO PARA RESOLUÇÃO DE EQUAÇÕES DIFERENCIAIS [1], [2], [3], [4] . . . . . . . . . . . . . 10

2.3.1 Método de Euler . . . . . . . . . . . . . . 13

2.3.2 Método de Runge-Kutta [1], [5] . . . . . . . . . . . 14

2.3 .3 Método Trapezoidal Implícito . . . . . . . . . . . . . . . . 16

3 FLUXO DE POTÊNCIA 18

3.1 O PROBLEMA DO FLUXO DE CARGA . . . . . . . . . . . 18

3.2 MÉTODO DE NEWTON-RAPHSON . . . . . . . . . . . 20

4 MODELAGEM PARA O PROBLEMA DE ESTABILIDADE 24

4.1 INTRODUÇÃO . . . . . . . . . . . . . . . . . . . . 24

4.2 MODELAGEM DO SISTEMA ELÉTRICO DE POTÊNCIA . . . . . . 24

4.2.1 Modelagem da Máquina Síncrona . . . . . . . . . . 25

4.2.2 Modelagem das Cargas do Sistema . . . . . . . . . . . . 29

4.3 METODOLOGIA . . . . . . . . . ......... 30 


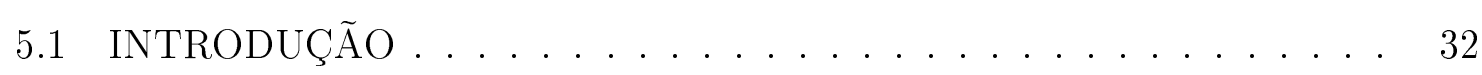

5.2 SISTEMA TESTE I . . . . . . . . . . . . . . . . . 32

5.3 SISTEMA TESTE II- 9 BARRAS E 3 MÁQUINAS SÍNCRONAS . . . 39

5.3.1 Distúrbio na Potência Mecânica do gerador 2 . . . . . . . . 42

5.3.2 Curto-circuito Trifásico na barra 7 sem desligamento da linha . 44

5.3.3 Curto-circuito Trifásico na barra 7 com desligamento de linha . 46

5.3.4 Correção do defeito após o tempo crítico . . . . . . . . . . 47

6 CONCLUSÕES $\quad 50$

6.1 CONSIDERAÇÕES FINAIS . . . . . . . . . . . . . . 50

6.2 SUGESTÕES PARA TRABALHOS FUTUROS . . . . . . . . . . . 51

A RESUlTAdos DAS SIMULAÇÕES

54 


\section{Lista de Tabelas}

5.1 Dados dos geradores do sistema de 3 barras . . . . . . . . . . 33

5.2 Dados de ligação-Linhas de Transmissão . . . . . . . . . . . . 40

5.3 Dados de ligação-Transformadores . . . . . . . . . . . . . . . . 40

5.4 Dados de barra . . . . . . . . . . . . . . . . . . . 41

5.5 Resultados do Fluxo de carga . . . . . . . . . . . . . . . . 41

5.6 Dados dos geradores . . . . . . . . . . . . . . . . 42 


\section{Lista de Figuras}

2.1 (a)Variação da potência em função do ângulo do rotor (b) Variação do ângulo do rotor em função do tempo $[1] \ldots \ldots \ldots$. . . . . . . . . 7

2.2 Sistema máquina-barra infinita e seu circuito equivalente utilizando o modelo clássico de gerador . . . . . . . . . . . . . . . 8

2.3 Ilustração gráfica para resolução numérica pelo método de Euler [1] . . . . . 13

4.1 Esquema ilustrativo de um sistema elétrico de potência . . . . . . . . . . . 24

4.2 Representação ilustrativa da máquina síncrona de dois pólos [6] . . . 25

4.3 Estrutura básica para o cálculo das variáveis relativas ao problema de estabilidade transitória . . . . . . . . . . . . . . 31

5.1 Sistema teste I . . . . . . . . . . . . . . . 33

5.2 Interface gráfica simulação. . . . . . . . . . . . . . . 36

5.3 Ângulo do rotor - tempo máximo para estabilidade. . . . . . . . . . . . . 37

5.4 Ângulo do rotor - Tempo mínimo para instabilidade. . . . . . . . . . . . . 37

5.5 Resultado da simulação para o modelo \#6 . . . . . . . . . . . 38

5.6 Circuito de 9 barras e 3 geradores $[7] \ldots \ldots \ldots$

5.7 Resposta de $\delta$, em valor absoluto, a uma perturbação em $P_{m} \quad \ldots$. . . . . 43

5.8 Resposta de $\delta$ a uma perturbação em $P_{m}$, referenciado ao gerador $1 \ldots$. . . . 43

5.9 Resposta de $\delta$ a um curto na barra 7 , em valor absoluto . . . . . . . . . 45

5.10 Resposta de $\delta$ a um curto na barra 7 , relativo ao gerador $1 \ldots \ldots$. . . . 45

5.11 Curva $\delta$ xt para um curto na barra 7 , com retirada da linha 5-7 . . . . . 46

5.12 Defasagem angular para um curto na barra 7, com retirada da linha 5-7 . . 47

5.13 Resposta de $\delta$ a uma perturbação em $P_{m}, t_{\text {falta }}=2,2 \mathrm{~s} \ldots \ldots \ldots$

5.14 Resposta de $\delta$ a um curto na barra $7, t_{\text {falta }}=0,7 \mathrm{~s} \ldots \ldots \ldots$

5.15 Defasagem Angular para um curto na barra 7 com retirada da linha 5-7,

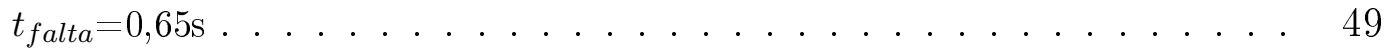


A.1 Simulação: Método de Euler . . . . . . . . . . . . . . 54

A.2 Simulação: Método de Runge-Kutta $2^{\mathrm{a}}$ ordem . . . . . . . . . . 55

A.3 Simulação: Método de Runge-Kutta $4^{\mathrm{a}}$ ordem . . . . . . . . . . . 56

A.4 Simulação: Modelo Clássico . . . . . . . . . . . . . 57

A.5 Simulação: Modelo \#3 . . . . . . . . . . . . . . . 58

A.6 Simulação: Modelo \#4 . . . . . . . . . . . . . . . . . . 59

A.7 Simulação: Modelo \#5 . . . . . . . . . . . . . . . . 60 


\section{LISTA DE SÍMBOLOS}

\begin{tabular}{|c|c|c|}
\hline Símbolo & Descrição & Unidade \\
\hline$E_{d}^{\prime}, E_{q}^{\prime}, E_{d}^{\prime \prime}, E_{q}^{\prime \prime}$ & $\begin{array}{l}\text { Tensão interna transiente e subtransiente do gerador nos } \\
\text { eixos direto }(d) \text { e quadratura }(q) \text {, respectivamente. }\end{array}$ & pu \\
\hline$E_{f d}$ & Tensão de campo do gerador. & $p u$ \\
\hline$H$ & Constante de inércia & $\frac{M W \cdot s}{M V A}$ \\
\hline$I_{d}, I_{q}$ & Corrente nos terminais dos geradores nos eixos $d$ e $q$. & pu \\
\hline$P_{e}$ & Potência elétrica. & $p u$ \\
\hline$P_{t}$ & Potência ativa na saída da máquina síncrona. & $p u$ \\
\hline$T_{e}$ & Torque elétrico. & $p u$ \\
\hline$T_{m}$ & Torque mecânico total da turbina. & $p u$ \\
\hline$R_{a}$ & Resistência do estator. & $p u$ \\
\hline$T_{d 0}^{\prime}, T_{q 0}^{\prime}, T_{d 0}^{\prime \prime}, T_{q 0}^{\prime \prime}$ & $\begin{array}{l}\text { Constante de tempo em circuito aberto transiente } \\
\text { e subtransiente do gerador nos eixos direto }(d) \text { e } \\
\text { quadratura }(q) \text {, respectivamente. }\end{array}$ & $s$ \\
\hline$V_{d}, V_{q}$ & Tensão do gerador nos eixos $d$ e $q$. & $p u$ \\
\hline$V_{t}$ & Tensão no terminal do gerador. & $p u$ \\
\hline$X_{d}^{\prime}, X_{q}^{\prime}, X_{d}^{\prime \prime}, X_{q}^{\prime \prime}$ & $\begin{array}{l}\text { Reatâncias transiente e subtransiente nos eixos direto }(d) \\
\text { e quadratura }(q), \text { respectivamente. }\end{array}$ & $p u$ \\
\hline$X_{p}$ & Reatância de Potier. & $p u$ \\
\hline$X_{l}$ & Reatância de Potier. & $p u$ \\
\hline$\delta$ & $\begin{array}{l}\text { Posição angular do rotor do gerador em relação ao } \\
\text { estator do mesmo. }\end{array}$ & rad \\
\hline$\omega_{r}$ & Velocidade do rotor. & $p u$ \\
\hline$\omega_{s}$ & Velocidade síncrona. & $p u$ \\
\hline
\end{tabular}




\begin{tabular}{llr} 
Símbolo & Descrição & Unidade \\
\hline$S_{i}$ & Potência nominal do i-ésimo gerador. & $p u$ \\
$f$ & Frequência. & $H z$
\end{tabular}

\section{Símbolos Gregos}

$\delta \quad$ Ângulo das barras internas do gerador.

$\Delta \quad$ Variação entre duas grandezas similares.

$\epsilon \quad$ Grau de tolerância específico.

$\theta \quad$ Angulo das barras.

$\omega \quad$ Velocidade ângular do rotor do gerador.

$\omega_{0} \quad$ Velocidade síncrona do sistema igual a $2 \pi f \mathrm{em} \frac{\mathrm{rad}}{\mathrm{s}}$.

$\theta_{i j} \quad$ Angulo entre as barras $i$ e $j$.

$\varphi \quad$ Pequeno número real positivo.

\section{Siglas}

CEPEL Centro de Pesquisas de Energia elétrica.

SEP Sistema Elétrico de Potência.

SIN Sistema Interligado Nacional.

ANAREDE Programa de Análise de Redes.

ANATEM Programa de Análise de Transitórios Eletromecânicos.

PacDyn Programa de Análise Dinâmica. 


\section{Capítulo 1 INTRODUÇÃO GERAL}

\subsection{Contextualização}

A análise de estabilidade de sistemas de potência tem como foco o estudo da capacidade de um determinado sistema de potência de se manter em sincronismo mesmo se submetido a grandes distúrbios. Devido à grande demanda de potência e energia requerida pelos consumidores, tanto no que diz respeito a redução de custos quanto em um sistema mais confiável, tornou-se gradualmente necessária uma interligação cada vez maior dos sistemas. Com essa crescente interligação, a operação torna-se bastante complexa, exigindo esforços computacionais cada vez mais elaborados. Neste contexto, técnicas mais eficientes e confiáveis de modelagem e integração numérica bem como diferentes estratégias de solução tem sido investigadas.

De acordo com [8], um sistema elétrico de potência é formado basicamente por geradores síncronos e cargas interligados por linhas de transmissão. O fluxo de potência ativa nas linhas está relacionado às diferenças entre os ângulos de fase dos geradores. Em condições normais de operação os alternadores estão na velocidade síncrona e existe um balanceamento entre a potência elétrica gerada e a potência mecânica proveniente das fontes primárias. Ou seja, o sistema opera em regime permanente, mantendo assim as diferenças entre os ângulos de fase constantes para que o fluxo de potência também seja constante.

O sistema permanecerá em equilíbrio até que alguma excitação o remova deste estado. Quando isso ocorrer, é imprescindível saber se o sistema encontrará uma situação de operação estável, mesmo aproximando-se de um novo ponto de equilíbrio, ou se afastará indefinidamente do ponto de operação inicial tornando-se instável.

Na realidade, um sistema interligado com grande número de máquinas está sujeito a 
pequenas perturbações, como variações de cargas nos barramentos. O estudo acerca desse tipo de perturbação é denominado estabilidade dinâmica. Este estudo pode ser realizado por meio de linearizações em torno de um ponto de operação estável permitindo aplicação de técnicas de analise de sistemas lineares.

Segundo [8], quando o sistema de potência é afetado por grandes perturbações, o estudo de estabilidade é conhecido como estabilidade transitória. Nessas situações, decorrentes de uma grande perturbação no sistema (caracterizada por defeitos do tipo: curtocircuito, desligamento de linhas de transmissão, perda de geração, ou uma combinação destes eventos), o equilíbrio entre a potência elétrica gerada e a potência mecânica de entrada é drasticamente rompida, principalmente nos geradores mais próximos eletricamente do defeito. Em conseqüência os rotores das máquinas sofrem diferentes acelerações levando, eventualmente, algumas delas a perda do sincronismo com o resto do sistema. Se as oscilações relativas dos diversos rotores tenderem a se amortecer fazendo o sistema como um todo atingir um novo estado de operação em regime permanente, então se diz que o ponto de operação inicial do sistema é estável a uma dada perturbação. Deve ser enfatizado que as condições do defeito têm forte influência na estabilidade do sistema. Por exemplo, um mesmo ponto de operação pode ser classificado como estável ou instável dependendo do tempo de extinção do curto-circuito ou do tempo de religamento de uma linha de transmissão. Se o ponto de operação for instável, a velocidade de pelo menos uma máquina tenderá progressivamente a se afastar das demais, ocasionando seu desligamento pelo sistema de proteção. De modo a evitar isso é essencial isolar o defeito ou até mesmo rejeitar algumas cargas para que este novo sistema mantenha-se estável. Para a situação estável é imprescindível a rápida eliminação da falta. O tempo máximo para que isso ocorra, é conhecido como tempo crítico de abertura, $t_{c}$.

Via de regra, os estudos de estabilidade transitória exigem modelos não-lineares e a técnica normalmente usada é a simulação ponto a ponto no tempo do comportamento dinâmico do sistema. 


\subsection{Objetivos}

Esta monografia tem por finalidade apresentar uma metodologia que propõe uma forma de cálcular das variáveis envolvidas no estudo da estabilidade transitória numéricamente. Os fenômenos abordados pela análise de estabilidade transitória são então são então simulados de acordo com o resultado destes cálculos. Esta metodologia é aplicada em dois casos: um sistema de 3 barras e um sistema de 9 barras.

É também objetivo deste projeto a elaboração de uma intereface que simplifique o processo de simulação e facilite a alteração de algum dado de interesse. A interface almeja a fácil assimilação dos resultados e a praticidade no seu manuseio. Cada tipo de modelagem estudada neste trabalho devem ter suas simulações abordadas na interface.

\subsection{Organização do trabalho}

No 2 é apresentado o problema de estabilidade transitória e todos os métodos que serão utilizados nos cálculos numéricos associados ao SEP.

Em seguida, no 3 é mostrado o cálculo do fluxo de carga, teoria fundamental para o cálculo das condições iniciais do SEP.

O 4 abrange a modelagem do sistema elétrico de potência, bem como a metodologia utilizada para os cálculos. Também são apresentados diversos tipos de modelos de geradores, estes, extraidos do PacDyn[9].

No 5 são apresentados os resultados das simulações utilizando os modelos e metodologias apresentados no capítulo 4 .

Por fim, no 6 são apresentadas as conclusões obtidas ao longo do desenvolvimento deste trabalho. 


\section{Capítulo 2 ANÁLISE DE ESTABILIDADE EM SISTEMAS ELÉTRICOS DE POTÊNCIA}

Neste capítulo é feita uma formulação analítica do problema, mostrando-se a forma geral dos sistemas de equações algébricas e diferenciais que descrevem o comportamento do sistema em estudos de estabilidade. São abordados os métodos de integração explícito (Euler e Runge-Kutta) e implícito (Trapezoidal) para o tratamento das equações diferenciais.

\subsection{FORMULAÇÃO GERAL DO PROBLEMA}

Um gerador síncrono é alimentado com energia mecânica fornecida por algum agente motor (seja a força das águas em hidrelétricas ou vapor em termoelétricas). Esta energia é então convertida em elétrica e transmitida à rede. A parte que não é convertida, transforma-se em potência de aceleração do rotor da máquina. Logo, o torque resultante na máquina é a diferença entre torque mecânico, cedido através do agente motor, e do torque elétrico, advindo das cargas através de campos magnéticos. Portanto [1]:

$$
T_{a}=T_{m}-T_{e}
$$

em que

$$
\begin{aligned}
& T_{a}=\text { Torque acelerante, em } N \cdot m \\
& T_{m}=\text { Torque mecânico, } \mathrm{em} N \cdot m \\
& T_{e}=\text { Torque elétrico, } \mathrm{em} N \cdot m
\end{aligned}
$$


Na equação 2.1, tanto $T_{m}$ quanto $T_{e}$ são positivos para o caso de um gerador e negativos para um motor.

O torque $T_{a}$ também pode ser escrito como a multiplicação do momento de inércia combinado do gerador e da turbina com a taxa de variação da velocidade angular do rotor. Desta forma, a equação 2.1 pode ser reescrita como:

$$
T_{a}=J \frac{d \omega_{m}}{d t}=T_{m}-T_{e}
$$

em que

$$
\begin{aligned}
& J=\text { momento de inércia }[\mathrm{kg} \cdot \mathrm{m}] \\
& \omega_{m}=\text { velocidade angular do rotor }[\mathrm{rad} / \mathrm{s}] \\
& t=\text { tempo }[\mathrm{s}]
\end{aligned}
$$

A equação 2.2 pode ser reformulada em termos da constante de inércia da máquina, H. Esta constante é definida como sendo o tempo necessário para a máquina sair do repouso e atingir a sua velocidade síncrona quando se aplica em seus terminais a potência aparente nominal.[10]

$$
H=\frac{1}{2} \frac{J \omega_{0 m}^{2}}{S_{B}}
$$

em que

$$
\begin{aligned}
& \omega_{0 m}=\text { velocidade síncrona, sendo que o } m \text { indica se tratar de uma grandeza } \\
& \text { mecânica }[\mathrm{rad} / \mathrm{s}] \\
& \S_{B}=\text { potência aparente nominal do gerador }[V A]
\end{aligned}
$$

Isolando $J$ tem-se:

$$
J=\frac{2 H S_{B}}{\omega_{0 m}^{2}}
$$


Ao substituir a equação 2.4 em 2.2, é gerada a equação de oscilação, chamada comumente de equação swing.

$$
\frac{2 H}{\omega_{0}} \frac{d \omega_{r}}{d t}=P_{m}-P_{e}
$$

Em 2.5, $\omega_{r}$ é a velocidade elétrica em $\mathrm{rad} / \mathrm{s}$.

Esta equação pode ser escrita de diversas formas. Para o presente estudo, o objetivo é avaliar as variações da velocidade. Considerando que a velocidade $\omega_{r 0}$ é constante, tem-se a equivalência $\frac{d \omega_{r}}{d t}=\frac{d \Delta \omega_{r}}{d t}$. É possível então reescrever a equação 2.5 na forma:

$$
\begin{aligned}
& \frac{d \Delta \omega_{r}}{d t}=\frac{1}{2 H}\left(P_{m}-P_{e}\right) \\
& \frac{d \delta}{d t}=\omega_{0} \Delta \omega_{r}
\end{aligned}
$$

em que

$$
\begin{aligned}
& \Delta \omega_{r}=\omega_{r}-\omega_{r 0}, \text { em } \mathrm{rad} / \mathrm{s} \\
& P_{m}=\text { Potência mecânica de entrada, em } p u \\
& P_{e}=\text { Potência elétrica de saída, em } p u \\
& \mathrm{H}=\text { Constante de inércia, em } M W s / M V A, \text { ou simplesmente } s \\
& \delta=\text { Ângulo do rotor em radianos } \\
& \mathrm{t}=\text { tempo, em } s
\end{aligned}
$$

\subsection{CRITÉRIO DAS ÁREAS IGUAIS}

A análise da estabilidade transitória de um sistema multimáquinas é feita por meio de programas que são embasados na resolução de integrações numéricas de equações matemáticas que representam as máquinas e os diversos componentes do sistema de potência. Quando verificado, por meio de integrações numéricas, que após ocorrer um distúrbio o ângulo entre duas maquinas oscilar em torno de uma posição de 
equilíbrio, o sistema tende a permanecer estável. Porém, quando esse ângulo crescer indefinidamente, o sistema torna-se instável. Informações a respeito do limite de estabilidade e do máximo ângulo de excursão $\left(\delta_{m}\right)$ podem ser analisadas por meio do gráfico Potência x ângulo, conforme mostrado na figura 2.1 [1]. Porém, em um sistema multimáquinas esta análise é complicada. É necessário observar oscilações subsequentes à primeira, pois é possível que ele perca seu sincronismo após a primeira oscilação [1], [11].

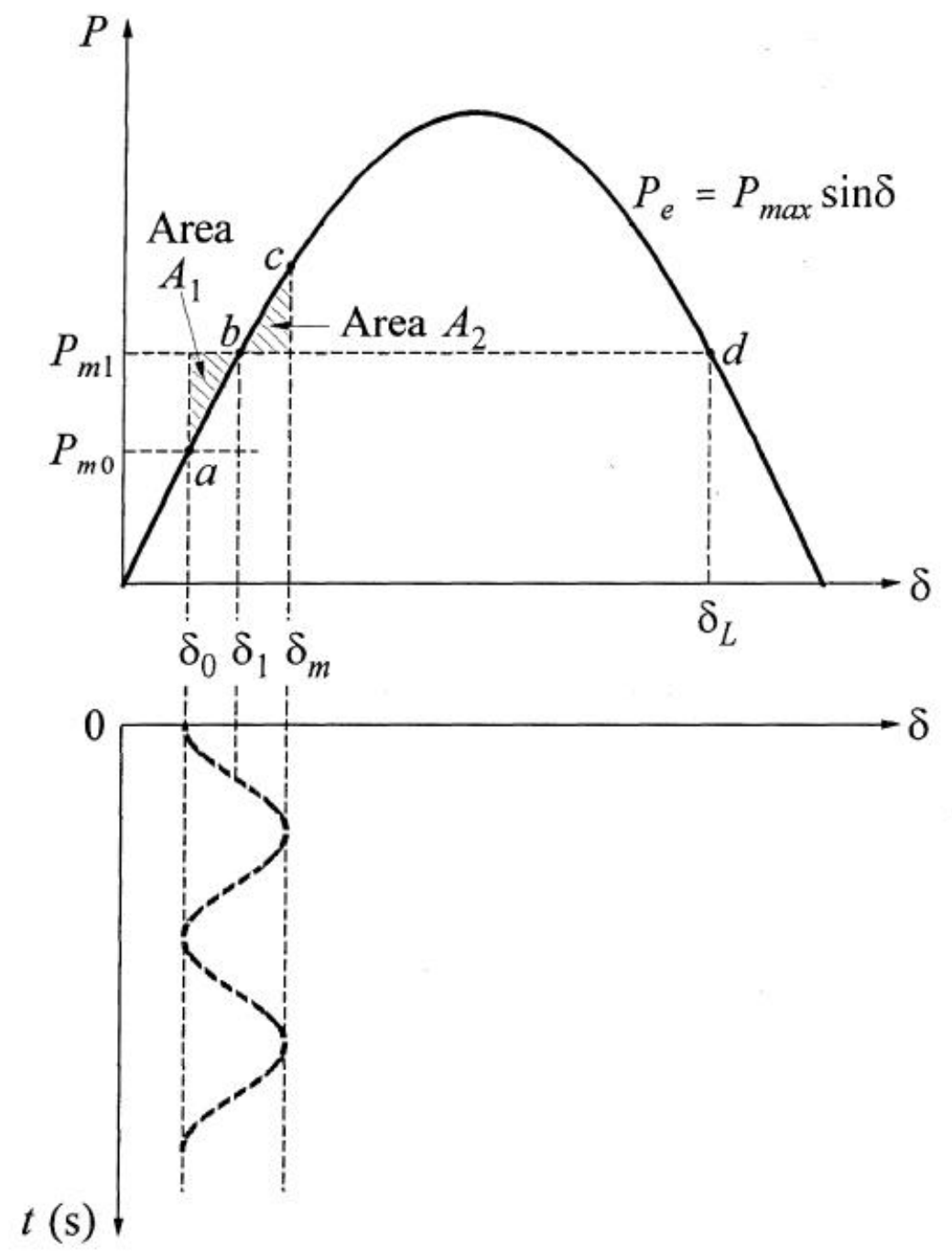

(a)

(b)

Figura 2.1: (a)Variação da potência em função do ângulo do rotor (b) Variação do ângulo do rotor em função do tempo [1]

Já em um sistema formado por duas máquinas ou até mesmo por uma máquina ligada a uma barra infinita, é possível analisar a estabilidade transitória do sistema, sem a necessidade de solucionar a equação de oscilação. Neste caso, pode ser aplicada uma técnica que proporciona uma excelente interpretação física dos fenômenos dinâmicos 
envolvidos no problema de estabilidade transitória e é embasada no conceito de energia do sistema, que é conhecido como critério das áreas iguais [8], [1], [11].

\subsubsection{Critério das Áreas Iguais para Sistema Máquina-Barra Infinita}

Um sistema de potência formado por uma máquina ligada a um barramento infinito, como representado na 2.2, baseia-se em um sistema onde a potência mecânica é constante, sendo o sistema considerado conservativo tendo em vista que as perdas por amortecimentos são desprezadas.

Seja a equação de oscilação 2.5 do sistema máquina - barra infinita e, sabendo que $\frac{d \delta}{d t}=\Delta \omega_{r}$, então:

$$
\frac{2 H}{\omega_{0}} \frac{d^{2} \delta}{d t^{2}}=P_{m}-P_{e}
$$

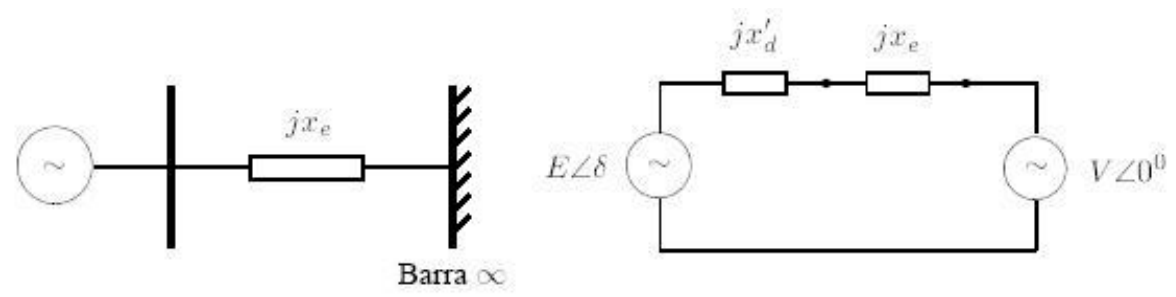

Figura 2.2: Sistema máquina-barra infinita e seu circuito equivalente utilizando o modelo clássico de gerador

A potência elétrica é aproximada por $P_{e}=P_{\max } \sin \delta$, onde $P_{\max }$ representa a potência elétrica máxima. Trata-se, portanto, de uma função não linear, e consequentemente a equação 2.8 não pode ser resolvida diretamente.

Multiplicando os dois lados da equação 2.8 por $\frac{d \delta}{d t}$, então:

$$
2 \frac{d \delta}{d t} \frac{d^{2} \delta}{d t^{2}}=\frac{\omega_{0}\left(P_{m}-P_{e}\right)}{H} \frac{d \delta}{d t}
$$


No entanto, já que:

$$
\frac{d}{d t}\left[\frac{d \delta}{d t}\right]^{2}=2 \frac{d \delta}{d t} \frac{d^{2} \delta}{d t^{2}}
$$

A Eq. 2.9 pode ser re-escrita como:

$$
\frac{d}{d t}\left[\frac{d \delta}{d t}\right]^{2}=\frac{\omega_{0}\left(P_{m}-P_{e}\right)}{H} \frac{d \delta}{d t}
$$

Integrando-se a Eq. 2.11, tem-se:

$$
\left[\frac{d \delta}{d t}\right]^{2}=\int \frac{\omega_{0}\left(P_{m}-P_{e}\right)}{H} d \delta
$$

De acordo com [1], a variação da velocidade $\frac{d \delta}{d t}$ só acontecerá quando ocorrer alguma perturbação no sistema. Porém, para operação estável, esta variação do ângulo $\delta$ deverá ser delimitada (conforme ponto c da figura 2.1), atingindo seu valor máximo e então alterando sua direção, no intuito de que a variação da velocidade $\frac{d \delta}{d t}$, em algum momento após o distúrbio, se torne nula. Sendo assim, a Eq. 2.12, pode ser escrita assim:

$$
\int_{\delta_{0}}^{\delta_{m}} \frac{\omega_{0}}{H}\left(P_{m}-P_{e}\right) d \delta=0
$$

Neste caso, $\delta_{0}$ e $\delta_{m}$ são os ângulos inicial e máximo respectivamente do rotor, conforme mostrado na figura 2.1. Portanto, o sistema se tornará estável quando a área abaixo da função $P_{m}-P_{e}$ em relação ao eixo $\delta$ for nula. Ou seja, isso ocorre quando a máquina começa a sofrer desaceleração, com o aumento da energia cinética sendo cedida à barra infinita, tornando assim a área A1 igual à área A2. Sendo que, na figura 2.1, a área A1 corresponde ao intervalo em que a potência elétrica é menor que a potência mecânica, enquanto a área A2 se refere a situação contrária. 
O ganho da energia cinética, pelo rotor, ocorre quando, na aceleração, $\delta$ muda de $\delta_{0}$ para $\delta_{1}$, sendo esse ganho representado por:

$$
E_{1}=\int_{\delta_{0}}^{\delta_{1}}\left(P_{m}-P_{e}\right) d \delta=A_{1}
$$

Já a energia perdida durante a desaceleração, ocorre quando $\delta$ muda de $\delta_{1}$ para $\delta_{m}$, e é representada por:

$$
E_{2}=\int_{\delta_{1}}^{\delta_{m}}\left(P_{e}-P_{m}\right) d \delta=A_{2}
$$

Não se considerando nenhuma perda de energia, a área A1 é igual a área A2, na situação crítica. Isso nos auxilia na determinação da estabilidade, através da solução formal da equação de oscilação do sistema formando assim a base para o critério das áreas iguais.

\subsection{MÉTODOS DE INTEGRAÇÃO PARA RESOLUÇÃO DE EQUAÇÕES DIFERENCIAIS [1], [2], [3], [4]}

Equações diferenciais, como $\frac{d x}{d t}=f(x, t)$, podem ser solucionadas por meio de métodos de integração numérica em um conjunto determinado de pontos como $t_{1}, t_{2}, t_{3}, \ldots, t_{n}$, $t_{n+1}, \ldots, t_{N}$, sendo $t_{0}$ e $t_{N}$ os pontos inicial e final, respectivamente. Considere-se que estes pontos possuem a mesma distância entre si, e que possam ser representados por:

$$
t_{n+1}-t_{n}=h
$$

onde $h$ é conhecido como passo de integração. Sendo assim, $x_{n+1}$ no ponto $t_{n+1}$ poderá ser calculado através de um único passo de integração a partir do ponto $x_{n}$ em $t_{n}$.

Métodos de integração que necessitam apenas de um valor para estimar a solução em cada intervalo de tempo são chamados de "métodos de passo único"ou ainda de 
"métodos de passo simples". Isso ocorre quando o valor de $x_{n}$ é necessário somente no ponto, $t=t_{n}$, para se obter $x_{n+1}$. Métodos que se enquadram nestas características são ditos auto-inicializáveis, o que é conveniente em instantes de descontinuidades, e têm como principais exemplos os métodos de Euler e Runge-Kutta.

Como cada um destes métodos apresentam equacionamentos distintos, quanto maior for a complexidade destes, maiores serão as exigências computacionais para o desenvolvimento de cada método.

Métodos de integração que requerem o conhecimento de valores de $x$ explicitamente de dois ou mais pontos, são chamados de "métodos de passo múltiplos". Como estes métodos usam informação sobre a solução anterior para dar inicio a cada passo de integração, eles são ditos não auto-inicializáveis. No entanto, como a maioria dos problemas de valor inicial não tem múltiplas condições iniciais, é necessário gerá-las anteriormente, para, assim então, ser possível a utilização do método de passo múltiplo.

Os métodos de integração numérica também são classificados como implícitos ou explícitos. Nos métodos explícitos, as fómulas de integração são aplicadas diretamente para cada uma das equações diferenciais individuais a serem resolvidas, e o valor da variável dependente $x$, para qualquer valor da variável independente $t$, é calculado a partir do conhecimento do valor anterior da variável independente. Os métodos de integração explícitos mais utilizados são os métodos de Euler e Runge-Kutta.

Já nos métodos implícitos, as equações diferenciais são algebrizadas, e assim, podendo ser resolvidas simultaneamente como um conjunto. Embora este método seja mais complexo para a resolução do equacionamento, ele possui uma maior estabilidade numérica. Os principais métodos de integração implícita são o método de AdamsBashford e o método trapezoidal.

Expressões explicitas também conhecidas como expressões do tipo aberta, a solução é obtida diretamente, enquanto expressões implícitas, fechada, processo interativo tornase necessário. Uma expressão do tipo aberta e uma do tipo fechada podem ser utilizadas conjuntamente, sendo a primeira preditora e a segunda corretora, e desta forma o 
método de integração é chamado de preditor - corretor.

A escolha por um método de integração para ser utilizado para resolução de equações diferenciais em estudos de estabilidade depende de diversos fatores, tais como: desempenho do método na presença de descontinuidades, estabilidade numérica, erros relacionados à discretização do problema, entre outros.

Como em qualquer resolução numérica de equações diferenciais, os erros tanto de arredondamento quanto os de truncamento existem. Os erros de arredondamento estão relacionados à própria insuficiência computacional em demonstrar operações de forma exata, em razão da sua aritmética de precisão finita. Já os erros de truncamento são causados pelo tipo de técnica utilizada para a atualização do valor da variável dependente, $x$.

Os erros de truncamento são determinados pela diferença entre o valor aproximado $x_{n}$ no ponto $t_{n}$, calculado pelo método adotado para a resolução, e o valor exato da solução da equação diferencial, $x\left(t_{n}\right)$, no ponto $t_{n}$. Esses erros podem ser reduzidos escolhendo-se um passo de integração pequeno. No entanto, quanto menor um passo de integração, maior será o número de interações necessárias, acarretando maiores erros de arredondamento acumulados. Neste sentido, existe um passo de integração ideal para cada caso, o que na pratica é bastante complicado de determinar.

Quando os erros não tendem a aumentar a cada passo de interação, diz-se que o procedimento é estável. Caso contrário, poderá surgir uma instabilidade numérica. Assim, é possível analisar a estabilidade de cada método, a medida que o número de passos de integração aumenta, pela diferença entre a solução esperada e a solução aproximada.

Neste trabalho utilizou-se os métodos explícitos de Euler e Runge-Kutta, e quando exigido do problema, por uma melhor precisão e eficiência dos resultados, o método Trapezoidal Implícito. 


\subsubsection{Método de Euler}

Considere a equação diferencial:

$$
\frac{d x}{d t}=f(x, t)
$$

Onde $x=x_{0}$ e $t=t_{0}$. A figura 2.3,[1], ilustra os princípios de aplicação do método de Euler.



Figura 2.3: Ilustração gráfica para resolução numérica pelo método de Euler [1]

Na figura 2.3, em $x=x_{0}, t=t_{0}$ pode-se supor que a reta tangente à curva $x^{\prime}=f(x, t)$ aproxima-se da curva solução sobre o intervalo $\left[x_{0}, x_{1}\right]$.

$$
\left.\frac{d x}{d t}\right|_{x=x_{0}}=f\left(x_{0}, t_{0}\right)
$$

Assim,

$$
f\left(x_{0}, t_{0}\right) \approx \lim _{\Delta t \rightarrow 0} \frac{x\left(t_{1}\right)-x\left(t_{0}\right)}{\Delta t}
$$

Portanto, temos que o valor de $\mathrm{x}$ em $t=t_{1}=t_{0}+\Delta t$ é dado por:

$$
x_{1}=x_{0}+\Delta t f\left(x_{0}, t_{0}\right)
$$


Esta relação pode ser generalizada para um ponto $i$ qualquer, resultando na forma de recorrência para solução de equações diferenciais pelo método de Euler:

$$
x_{i}=x_{i-1}+\Delta t f\left(x_{i-1}, t_{i-1}\right)
$$

Como este método considera apenas a primeira derivada de $x$, este é referido como método de primeira ordem.

\subsubsection{Método de Runge-Kutta [1], [5]}

Os métodos de Runge-Kutta aproximam-se bastante da série de Taylor. No entanto, algumas dificuldades da série de Taylor, como a exigência de uma avaliação explicita das derivadas de elevadas ordens podem ser contornadas. Para isso, o método faz uso da estratégia de calcular os valores de $f(x, t)$ em pontos intermediários para cada passo de integração da equação diferencial.

Diferente dos demais métodos de integração, uma vez que cada valor de $x$ é determinado pelas fórmulas de maneira unívoca, este método não exige repetidas aproximações. Sua principal vantagem é que conhecendo apenas a solução da função em seu ponto inicial, se pode determinar os seus valores nos pontos seguintes.

Os métodos de Runge-Kutta podem ser de diferentes ordens, dependendo do número de termos efetivamente retido na série de Taylor.

\subsubsection{Método Runge-Kutta segunda ordem}

Com base na equação diferencial $\frac{d x}{d t}=f(x, t)$, para o valor de $\mathrm{x}$ em $t=t_{0}+\Delta t$, tem-se a seguinte fórmula para o método:

$$
x_{1}=x_{0}+\Delta x=x_{0}+\frac{k_{1}+k_{2}}{2}
$$


onde

$$
\begin{aligned}
& k_{1}=f\left(x_{0}, t_{0}\right) \Delta t \\
& k_{2}=f\left(x_{0}+k_{1}, t_{0}+\Delta t\right) \Delta t
\end{aligned}
$$

Este método é equivalente a considerar os termos da primeira e segunda derivada da série de Taylor, desconsiderando-se os termos de terceira ordem em diante, provocando erros nessa magnitude.

A solução de $x$, para os demais passos de integração, pode ser representada, de forma generalizada, pela equação:

$$
x_{n+1}=x_{n}+\frac{k_{1}+k_{2}}{2}
$$

em que

$$
\begin{aligned}
& k_{1}=f\left(x_{n}, t_{n}\right) \Delta t \\
& k_{2}=f\left(x_{n}+k_{1}, t_{n}+\Delta t\right) \Delta t
\end{aligned}
$$

\subsubsection{Método Runge-Kutta quarta ordem}

O método de Runge-Kutta em ordem superior usa médias ponderadas da função $f$ calculada nos extremos e em pontos intermediários do intervalo $\left[t_{n}, t_{n+1}\right]$.

A solução de $x$ para este método pode ser calculada através da seguinte equação:

$$
x_{n+1}=x_{n}+\frac{1}{6}\left(k_{1}+2 k_{2}+2 k_{3}+k_{4}\right)
$$

Em que $x_{n+1}$ é a aproximação de $x\left(t_{n+1}\right)$ e 


$$
\begin{aligned}
& k_{1}=f\left(x_{n}, t_{n}\right) \Delta t \\
& k_{2}=f\left(x_{n}+\frac{k_{1}}{2}, t_{n}+\frac{\Delta t}{2}\right) \Delta t \\
& k_{3}=f\left(x_{n}+\frac{k_{2}}{2}, t_{n}+\frac{\Delta t}{2}\right) \Delta t \\
& k_{4}=f\left(x_{n}+k_{3}, t_{n}+\Delta t\right) \Delta t
\end{aligned}
$$

A interpretação física da solução acima é a seguinte [1]:

- $k_{1}=$ (inclinação no inicio da etapa) $\Delta t$

- $k_{2}=$ (primeira aproximação da inclinação na etapa intermediária, usando a inclinação $k_{1}$ para determinar o valor de $x$ no ponto $\left.t_{n}+\Delta t\right) \Delta t$

- $k_{3}=$ (segunda aproximação da inclinação na etapa intermediaria, porém usando a inclinação $k_{2}$ para determinar o valor de $\left.x\right) \Delta t$

- $k_{4}=($ inclinação no final da etapa) $\Delta t$.

$$
\Delta x=\frac{1}{6}\left(k_{1}+2 k_{2}+2 k_{3}+k_{4}\right)
$$

Na qual $\Delta x$ é o valor incremental de $x$, dado pela média ponderada das estimativas baseadas nas inclinações, no início, meio e fim, do intervalo de tempo.

Este método é equivalente a considerar os termos até a $4^{\text {a }}$ derivada da série de Taylor, que tem um erro da ordem de $\Delta t^{5}$.

\subsubsection{Método Trapezoidal Implícito}

Considere-se a seguinte equação diferencial:

$$
\frac{d x}{d t}=f(x, t)
$$


do qual se deseja obter a solução no instante $t_{n+1}$ a partir de sua solução conhecida no instante $t_{n}$.

Integrando-se a equação 2.28 no intervalo $t_{n}$ a $t_{n+1}$, obtém-se:

$$
x_{n+1}=x_{n}+\int_{t_{n}}^{t_{n}+1} f(x, \tau) d \tau
$$

A integral da eq. 2.29 pode ser aproximada por:

$$
\int_{t_{n}}^{t_{n+1}} f(x, \tau) d \tau=\frac{f\left(x_{n+1}, t_{n+1}\right)+f\left(x_{n}, t_{n}\right)}{2} \Delta t
$$

onde $\Delta t=t_{n+1}-t_{n}$.

Desta forma, da equação 2.29 tem-se:

$$
x_{n+1}=x_{n}+\frac{f\left(x_{n+1}, t_{n+1}\right)+f\left(x_{n}, t_{n}\right)}{2} \Delta t
$$

Os métodos de integração implícitos usam uma interpolação de funções para uma expressão sob uma integral. A interpolação implica que as funções devem passar através dos pontos ainda desconhecidos no instante $t_{n+1}[1]$.

A aplicação desse método de solução numérica de equações diferenciais, sempre resulta em uma equação algébrica que depende do seu resultado anterior, ou seja, trata-se de equações algébricas recursivas. As equações algébricas recursivas são chamadas equações de diferenças (uma analogia às equações diferenciais). Assim, um sistema de equações diferenciais transformado em um sistema algébrico, pode ser resolvido simultaneamente, o que faz dos métodos implícitos serem muitas das vezes mais adequados do que os métodos explícitos. 


\section{Capítulo 3 FLUXO DE POTÊNCIA}

O cálculo do fluxo de potência de um determinado sistema tem por objetivo determinar as tensões nas barras, bem como as potências ativa e reativa que fluem pelas linhas de transmissão em regime permanente. Para este trabalho, foi utilizado o método de Newton-Raphson como apresentado em [12]. Neste capítulo mostra-se como é aplicado o método ao sistema de equações não lineares que modela o SEP.

\subsection{O PROBLEMA DO FLUXO DE CARGA}

Após a obtenção dos dados do sistema e a transformação dos mesmos para pu, monta-se a matriz $Y_{B U S}$. Por conveniência, escreve-se a $Y_{B U S}$ em termos das suas componentes reais e imaginárias, definidas como segue:

$$
\overline{\mathbf{Y}}_{\mathrm{ij}}=\mathbf{G}_{\mathrm{ij}}+j \mathbf{B}_{\mathrm{ij}}
$$

$$
\begin{aligned}
i & =1,2, \ldots, \mathrm{n} \\
j & =1,2, \ldots, \mathrm{n} \\
n & =\text { número de barras do sistema }
\end{aligned}
$$

Seguindo a representação descrita acima e amparado pela lei de Kirchhoff para correntes, a injeção de corrente na barra $k$ é dada por:

$$
\begin{aligned}
& \overline{\mathbf{I}}_{\mathbf{k}}=\sum_{m \epsilon K} \overline{\mathbf{Y}}_{\mathbf{k m}} \overline{\mathbf{V}}_{\mathbf{m}} \\
& \overline{\mathbf{I}}_{\mathbf{k}}=\sum_{m \epsilon K}\left(\mathbf{G}_{\mathbf{k m}}+j \mathbf{B}_{\mathbf{k m}}\right)\left(V_{m} \angle \theta_{m}\right)
\end{aligned}
$$


onde $K$ é o conjunto de todas as $m$ barras interligadas à barra $k$ mais a própria barra $k$.

Desta forma, a injeção de potência complexa na barra $k, \bar{S}_{k}$, é dada por:

$$
\overline{\mathbf{S}}_{\mathbf{k}}^{*}=\mathbf{P}_{\mathbf{k}}-j \mathbf{Q}_{\mathbf{k}}=\overline{\mathbf{V}}_{\mathbf{k}}^{*} \overline{\mathbf{I}}_{\mathbf{k}}
$$

Substituindo-se 3.3 em 3.4 determina-se:

$$
\overline{\mathbf{S}}_{\mathbf{k}}^{*}=\left(V_{k} \angle-\theta_{k}\right) \sum_{m \in K}\left(G_{k m}+j B_{k m}\right)\left(V_{m} \angle \theta_{m}\right)
$$

Separando-se a parte real e imaginária da expressão 3.5, encontram-se as injeções de potência ativa $P_{k}$ e reativa $Q_{k}$ na barra $k$ :

$$
\begin{aligned}
P_{k} & =V_{k} \sum_{m \epsilon K} V_{m}\left(G_{k m} \cos \theta_{k m}+B_{k m} \sin \theta_{k m}\right) \\
Q_{k} & =V_{k} \sum_{m \epsilon K} V_{m}\left(G_{k m} \sin \theta_{k m}-B_{k m} \cos \theta_{k m}\right)
\end{aligned}
$$

onde $\theta_{k m}$ é a diferença do ângulo das tensões na barra $k$ e na barra $m$.

Em um sistema elétrico de potência são conhecidos as potências ativa $\left(P_{k}\right)$ e reativa $\left(Q_{k}\right)$ das barras de carga PQ; a potência ativa $\left(P_{k}\right)$ e o módulo da tensão $\left(V_{k}\right)$ para as barras de geração PV; e a magnitude da tensão $\left(V_{k}\right)$, bem como o ângulo da tensão $\left(\theta_{k}\right)$ da barra de referência do sistema. Desta forma, o problema do cálculo do fluxo de carga se resume à determinação de:

- $V_{k}$ e $\theta_{k}$ nas barras $P Q$;

- $\theta_{k}$ e $Q_{k}$ nas barras $Q V$

- $P_{k}$ e $Q_{k}$ na barra de referência. 
O sistema de equações algébricas não-lineares 3.6 pode ser resolvido de diversos métodos. Um dos métodos mais eficientes nesse cálculo é o método de NewtonRaphson.

O fluxo de carga neste trabalho utiliza o software MATPOWER, desenvolvido na universidade de Cornell. O cálculo das condições iniciais das barras para o problema de estabilidade utiliza este aplicativo.

\subsection{MÉTODO DE NEWTON-RAPHSON}

Baseado em linearizações sucessivas das funções, o método de Newton-Raphson é de fundamental importância para a resolução de sistemas de equações algébricas não lineares. Estas linearizações são motivadas a partir de uma condição inicial arbitrária e obtidas através da expansão em série de Taylor.

A vantagem na utilização deste método é a velocidade com que o processo ocorre. Isto é devido ao fato de que a convergência é quadrática, fazendo com que poucas interações sejam necessárias. Além disso, a convergência independe da dimensão do sistema. Uma grande desvantagem do método é a necessidade de montar a matriz Jacobiana.

Seja o sistema de equações não lineares [3]:

$$
\begin{gathered}
f_{1}\left(x_{1}, x_{2}, \ldots, x_{n}\right)=0 \\
f_{2}\left(x_{1}, x_{2}, \ldots, x_{n}\right)=0 \\
\vdots \\
f_{n}\left(x_{1}, x_{2}, \ldots, x_{n}\right)=0
\end{gathered}
$$

sendo:

$f_{n}$ - n-ésima função a resolver; $x_{1}, x_{2}, \ldots, x_{n}$ - variáveis do problema 
Representando o sistema de forma vetorial:

$$
\overline{\mathbf{F}}(\overline{\mathbf{x}})=\left[f_{1}(x), f_{2}(x), \ldots, f_{n}(x)\right]^{T}
$$

e o vetor da incógnita $\overline{\mathbf{x}}$ representado por:

$$
\overline{\mathbf{x}}=\left[\begin{array}{llll}
x_{1} & x_{2} & \ldots & x_{n}
\end{array}\right]^{T}
$$

Considerando que $x_{1}^{0}, x_{2}^{0}, \ldots, x_{n}^{0}$ são soluções para a estimativa inicial das equações acima, o erro do valor verdadeiro em relação à estimativa inicial das soluções pode ser representado por:

$$
\Delta x_{n}=x_{n}-x_{n}^{(0)}
$$

em que:

$$
\begin{aligned}
& x_{n}^{(0)} \text { - estimativa inicial de } x_{n} ; \\
& x_{n} \text { - valor correto de } x_{n} \text { para a solução; } \\
& \Delta x_{n} \text { - erro entre a estimativa inicial e o valor correto. }
\end{aligned}
$$

Assim, recorrendo-se à expansão da série de Taylor, pode-se reescrever cada elemento de $\overline{\mathbf{F}}(\overline{\mathbf{x}})$, de forma linearizada, da seguinte maneira:

$$
f_{n}\left(x_{1}^{(0)}, x_{2}^{(0)}, \ldots, x_{n}^{(0)}\right)+\left.\Delta x_{1}^{(0)} \frac{\partial f_{n}}{\partial x_{1}}\right|_{(0)}+\left.\Delta x_{2}^{(0)} \frac{\partial f_{n}}{\partial x_{2}}\right|_{(0)}+\ldots+\left.\Delta x_{n}^{(0)} \frac{\partial f_{n}}{\partial x_{n}}\right|_{(0)} \approx 0
$$

sendo:

$\left.\frac{\partial f_{n}}{\partial x_{n}}\right|_{(0)}$ - Derivada parcial da n-ésima função em relação a n-ésima variável no instante inicial. 
Como as derivadas de ordem superior a um, pelo método de Newton-raphson, não são consideradas, a equação acima pode ser representada na forma matricial por:

$$
\left[\begin{array}{c}
-f_{1}\left(x_{1}^{(0)}, x_{2}^{(0)}, \ldots, x_{n}^{(0)}\right) \\
-f_{2}\left(x_{1}^{(0)}, x_{2}^{(0)}, \ldots, x^{(0)}\right) \\
\vdots \\
-f_{n}\left(x_{1}^{(0)}, x_{2}^{(0)}, \ldots, x_{n}^{(0)}\right)
\end{array}\right]=\left[\begin{array}{cccc}
\frac{\partial f_{1}}{\partial x_{1}} & \frac{\partial f_{1}}{\partial x_{2}} & \ldots & \frac{\partial f_{1}}{\partial x_{n}} \\
\frac{\partial f_{2}}{\partial x_{1}} & \frac{\partial f_{2}}{\partial x_{2}} & \ldots & \frac{\partial f_{2}}{\partial x_{n}} \\
\vdots & \vdots & \ddots & \vdots \\
\frac{\partial f_{n}}{\partial x_{1}} & \frac{\partial f_{n}}{\partial x_{2}} & \ldots & \frac{\partial f_{n}}{\partial x_{n}}
\end{array}\right]\left[\begin{array}{c}
\Delta x_{1}^{(0)} \\
\Delta x_{2}^{(0)} \\
\vdots \\
\Delta x_{n}^{(0)}
\end{array}\right]
$$

Em que a matriz das derivadas parciais é dada por:

$$
J=\frac{\partial \overline{\mathbf{F}}}{\partial x}=\left[\begin{array}{cccc}
\frac{\partial f_{1}}{\partial x_{1}} & \frac{\partial f_{1}}{\partial x_{2}} & \cdots & \frac{\partial f_{1}}{\partial x_{n}} \\
\frac{\partial f_{2}}{\partial x_{1}} & \frac{\partial f_{2}}{\partial x_{2}} & \cdots & \frac{\partial f_{2}}{\partial x_{n}} \\
\vdots & \vdots & \ddots & \cdots \\
\frac{\partial f_{n}}{\partial x_{1}} & \frac{\partial f_{n}}{\partial x_{2}} & \cdots & \frac{\partial f_{n}}{\partial x_{n}}
\end{array}\right]
$$

O vetor de correção $\Delta \bar{x}^{\gamma}$ é calculado impondo-se que, para a iteração $\gamma$,

$$
\overline{\mathbf{F}}\left(\overline{\mathbf{x}}^{(\gamma)}\right)+\mathbf{J}\left(\overline{\mathbf{x}}^{\gamma}\right) \Delta \overline{\mathbf{x}}^{\gamma}=0
$$

O algoritmo utilizado para resolução do sistema de equações $\mathbf{F}(x)=0$ pelo método de Newton é [12]:

1. Fazer $\gamma=0$ e escolher uma solução inicial $\overline{\mathbf{x}}=\overline{\mathbf{x}}^{(\gamma)}=\overline{\mathbf{x}}^{(\mathbf{0})}$;

2. Calcular $\overline{\mathbf{F}}\left(\overline{\mathbf{x}}^{(\gamma)}\right)$;

3. Testar convergência: se $\left\|\overline{\mathbf{F}}_{\mathbf{i}}\left(\overline{\mathbf{x}}^{(\gamma)}\right)\right\| \leq \varepsilon$, o processo convergiu para solução $\overline{\mathbf{x}}^{(\gamma)}$, caso contrário, passar para (4).

4. Calcular matriz jacobiana $J\left(\overline{\mathbf{x}}^{\gamma}\right)$. 
5. Determinar nova solução $\overline{\mathbf{x}}^{\gamma+\mathbf{1}}$ :

$$
\begin{array}{r}
\overline{\mathbf{x}}^{\gamma+\mathbf{1}}=\overline{\mathbf{x}}^{\gamma}+\Delta \overline{\mathbf{x}}^{\gamma} \\
\Delta \overline{\mathbf{x}}^{\gamma}=-\left[J\left(\overline{\mathbf{x}}^{\gamma}\right)\right]^{-1} \overline{\mathbf{F}}\left(\overline{\mathbf{x}}^{\gamma}\right)
\end{array}
$$

6. Fazer $\gamma+1 \rightarrow \gamma$ e voltar para o passo (2). 


\section{Capítulo 4 MODELAGEM PARA O PROBLEMA DE ESTABILIDADE}

\subsection{INTRODUÇÃO}

Para o estudo de estabilidade transitória de um sistema elétrico de potência é necessário modelos para representar matematicamente seus componentes, como, por exemplo, as máquinas síncronas e linhas de transmissão. Neste capítulo, apresenta-se o equacionamento dos componentes do sistema.

\subsection{MODELAGEM DO SISTEMA ELÉTRICO DE POTÊNCIA}



Figura 4.1: Esquema ilustrativo de um sistema elétrico de potência

Um sistema elétrico de potência genérico, como o da figura 4.1, pode ser descrito pela equação de injeção de corrente, que se segue:

$$
\bar{I}=\left[Y_{B U S}\right] \bar{V}
$$


em que $Y_{B U S}$ é a matriz de admitância do sistema, $\bar{I}$ é o vetor das correntes injetadas nas $n$ barras e $\bar{V}$ é o vetor de tensão em cada barra. Cada elemento das matrizes $\bar{I}$ e $\bar{V}$ pode ainda ser representado tanto em seu formato fasorial, quanto seu formato retangular:

$$
\begin{gathered}
\bar{V}_{i}=V_{i} \angle \theta_{i}=V_{r i}+j V_{m i} \\
\bar{I}_{i}=I_{i} \angle \theta_{i}=I_{r i}+j I_{m i}
\end{gathered}
$$

com $i=1,2, \ldots, n$, em que $n$ é o número de barras do sistema.

\subsubsection{Modelagem da Máquina Síncrona}

Para os estudos de estabilidade, o gerador síncrono é considerado o elemento mais importante do sistema. Ele tem o papel de fornecer energia elétrica às cargas do sistema. O modelamento, no entanto, pode ser feito através de vários modelos, dependendo do tipo de máquina e de suas cargas. Neste trabalho, o gerador síncrono é representado pelos seis primeiros modelos utilizados no software Pacdyn, um programa desenvolvido pelo CEPEL para estudo de estabilidade a pequenos sinais. [9]

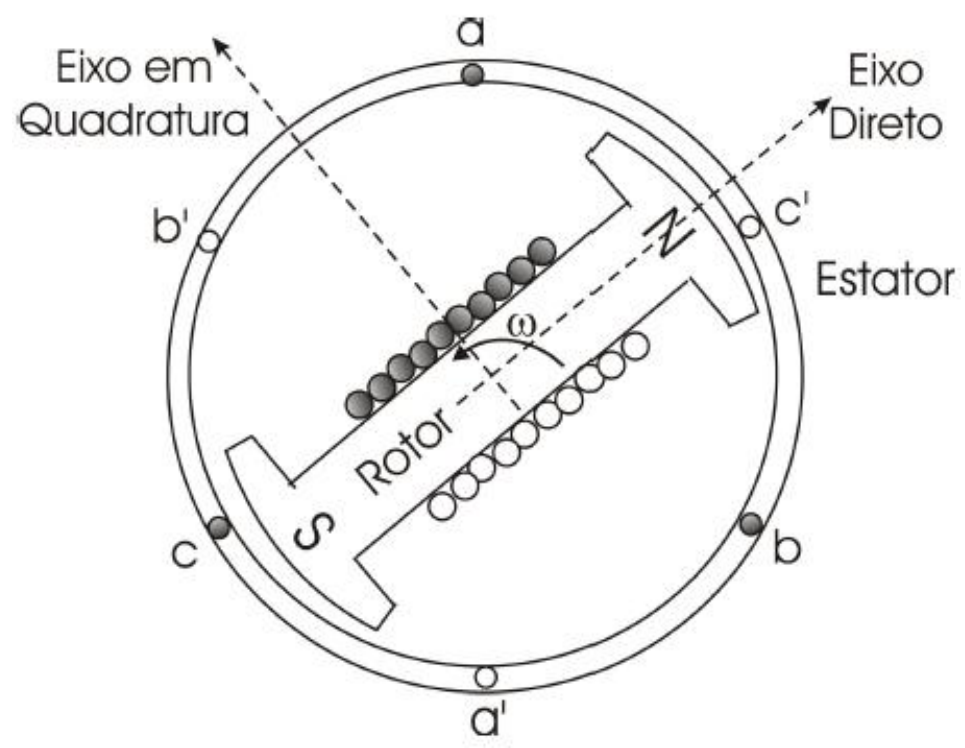

Figura 4.2: Representação ilustrativa da máquina síncrona de dois pólos [6] 
Apesar de vários modelos, utiliza-se algumas características em comum, bem como certos procedimentos para facilitar os cálculos. Nas equações elétricas do gerador, temos que a tensão e a corrente são função da posição $\theta$ do rotor em relação a uma referência fixa ao estator [13]. Pode-se simplificar o sistema ao se representar as variáveis dos enrolamentos do estator utilizando enrolamentos fictícios $d$ e $q$ em sincronismo com o rotor (veja figura 4.2). Essa simplificação é feita utilizando-se a Transformada de Park, a qual pode referenciar tanto as tensões, quanto as correntes aos eixos fictícios direto $(d)$ e em quadratura $(q)$ :

$$
\left[\begin{array}{c}
I_{d i} \\
I_{q i}
\end{array}\right]=\left[\begin{array}{cc}
\sin \delta_{i} & -\cos \delta_{i} \\
\cos \delta_{i} & \sin \delta_{i}
\end{array}\right]\left[\begin{array}{c}
I_{r i} \\
I_{m i}
\end{array}\right]
$$

Transformação da Corrente $x-y \rightarrow d-q$

$$
\left[\begin{array}{c}
V_{d i} \\
V_{q i}
\end{array}\right]=\left[\begin{array}{cc}
\sin \delta_{i} & -\cos \delta_{i} \\
\cos \delta_{i} & \sin \delta_{i}
\end{array}\right]\left[\begin{array}{c}
V_{r i} \\
V_{m i}
\end{array}\right]
$$

Transformação da Tensão $x-y \rightarrow d-q$

onde $i$ representa a barra do gerador no sistema elétrico de potência.

As seguintes equações são comuns a todos os modelos abordados:

- Módulo da tensão nos terminais do gerador

$$
V_{t}^{2}=V_{d}^{2}+V_{q}^{2}
$$

- Potência ativa nos terminais do gerador

$$
P_{t}=V_{d} \cdot I_{d}+V_{q} \cdot I_{q}
$$

- Potência elétrica interna do gerador

$$
P_{e}=P_{t}+R_{a}\left(I_{d}^{2}+I_{q}^{2}\right)
$$

- Equação Swing

$$
\begin{aligned}
& \frac{d \Delta \omega_{r}}{d t}=\frac{1}{2 H}\left(P_{m}-P_{e}\right) \\
& \frac{d \delta}{d t}=\omega_{0} \Delta \omega_{r}
\end{aligned}
$$


Nas equações 4.9 e 4.10, $\Delta \omega_{r}$ está em $p u$.

\subsubsection{Modelos do PACDYN}

As equações dos modelos de \#2 a \#6 do PacDyn [9], foco do nosso estudo, tem suas equações apresentadas abaixo:

Modelo \#2

$$
\begin{aligned}
& V_{d}=E_{d}^{\prime}+\left(\frac{X_{q}^{\prime}-X_{p}}{S A T_{q}}+X_{p}\right) I_{q}-R_{a} I_{d} \\
& V_{q}=E_{q}^{\prime}+\left(\frac{X_{d}^{\prime}-X_{p}}{S A T_{d}}+X_{p}\right) I_{d}-R_{a} I_{q} \\
& \frac{d E_{q}^{\prime}}{d t}=\frac{1}{T_{d 0}^{\prime}}\left[E_{f d}-\left(X_{d}-X_{d}^{\prime}\right) I_{d}-E_{q}^{\prime} S A T_{d}\right]
\end{aligned}
$$

As equações de saturação para máquinas síncronas do modelo \#2 são:

$$
\begin{aligned}
& C_{d}=\frac{S F A C-1,2}{1,2^{7}} \\
& S A T_{d}=C_{d}\left(V_{q}+R_{a} I_{q}+X_{p} I_{d}\right)^{6} \\
& S A T_{q}=\frac{X_{q}}{X_{d}} C_{d}\left(V_{d}+R_{a} I_{d}-X_{p} I_{q}\right)^{6}
\end{aligned}
$$

\section{Modelo \#3}

$$
\begin{aligned}
& V_{d}=E_{d}^{\prime}+\left(\frac{X_{q}^{\prime}-X_{p}}{S A T_{q}}+X_{p}\right) I_{q}-R_{a} I_{d} \\
& V_{q}=E_{q}^{\prime}-\left(\frac{X_{d}^{\prime}-X_{p}}{S A T_{d}}+X_{p}\right) I_{d}-R_{a} I_{q} \\
& \frac{d E_{d}^{\prime}}{d t}=\frac{1}{T_{q 0}^{\prime}}\left[\left(X_{q}-X_{q}^{\prime}\right) I_{q}-E_{d}^{\prime} S A T_{q}\right] \\
& \frac{d E_{q}^{\prime}}{d t}=\frac{1}{T_{d 0}^{\prime}}\left[E_{f d}-\left(X_{d}-X_{d}^{\prime}\right) I_{d}-E_{q}^{\prime} S A T_{d}\right]
\end{aligned}
$$


As equações de saturação para máquinas síncronas do modelo \#3 são:

$C_{d}=\frac{S F A C-1,2}{1,2^{7}}$

$S A T_{d}=C_{d}\left(V_{q}+R_{a} I_{q}+X_{p} I_{d}\right)^{6}$

$S A T_{q}=\frac{X_{q}}{X_{d}} C_{d}\left(V_{d}+R_{a} I_{d}-X_{p} I_{q}\right)^{6}$

Modelo \#4

$V_{d}=E_{d}^{\prime}+\left(\frac{X_{q}^{\prime}-X_{p}}{S A T_{q}}+X_{p}\right) I_{q}-R_{a} I_{d}$

$V_{q}=E_{q}^{\prime}-\left(\frac{X_{d}^{\prime}-X_{p}}{S A T_{d}}+X_{p}\right) I_{d}-R_{a} I_{q}$

$\frac{d E_{q}^{\prime}}{d t}=\frac{1}{T_{d 0}^{\prime}}\left[E_{f d}-\left(X_{d}-X_{d}^{\prime}\right) I_{d}-E_{q}^{\prime} S A T_{d}\right]$

$\frac{d E_{d}^{\prime \prime}}{d t}=\frac{1}{T_{q 0}^{\prime \prime}}\left[\left(X_{q}-X_{q}^{\prime \prime}\right) I_{q}-E_{d}^{\prime \prime} S A T_{q}\right]$

$\frac{d E_{q}^{\prime \prime}}{d t}=\frac{1}{T_{d 0}^{\prime \prime}}\left[E_{q}^{\prime} S A T_{d}-\left(X_{d}^{\prime}-X_{d}^{\prime \prime}\right) I_{d}-E_{q}^{\prime \prime} S A T_{d}\right]$

As equações de saturação para máquinas síncronas do modelo \#4 são:

$C_{d}=\frac{S F A C-1,2}{1,2^{7}}$

$S A T_{d}=C_{d}\left(V_{q}+R_{a} I_{q}+X_{p} I_{d}\right)^{6}$

$S A T_{q}=\frac{X_{q}}{X_{d}} C_{d}\left(V_{d}+R_{a} I_{d}-X_{p} I_{q}\right)^{6}$

Modelo \#5

$V_{d}=E_{d}^{\prime \prime}+X_{q}^{\prime} I_{q}-R_{a} I_{d}$

$V_{q}=E_{q}^{\prime \prime}-X{ }_{d} I_{d}-R_{a} I_{q}$

$\frac{d E_{d}^{\prime}}{d t}=\frac{1}{T_{q}^{\prime} 0}\left[\frac{X_{q}-X_{q}^{\prime}}{X_{q}^{\prime}-X_{l}} E_{d}^{\prime \prime}-\frac{X_{q}-X_{l}}{X_{q}^{\prime}-X_{l}} E_{d}^{\prime}+\frac{\left(X_{q}-X_{q}^{\prime}\right)\left(X_{q}^{\prime \prime}-X_{l}\right)}{X_{q}^{\prime}-X_{l}} I_{q}+S A T_{q}\right]$

$\frac{d E_{q}^{\prime}}{d t}=\frac{1}{T_{d}^{\prime} 0}\left[E_{f d} \frac{X_{d}-X_{d}^{\prime}}{X_{d}^{\prime}-X_{l}} E_{q}^{\prime}-\frac{X_{d}-X_{l}}{X_{d}^{\prime}-X_{l}} E_{q}^{\prime}-\frac{\left(X_{d}-X_{d}^{\prime}\right)\left(X_{d}^{\prime}-X_{l}\right)}{X_{d}^{\prime}-X_{l}} I_{d}-S A T_{d}\right]$

$\frac{d E_{d}^{\prime \prime}}{d t}=\frac{1}{T_{q}^{\prime \prime} 0}\left[-E_{d}^{\prime \prime}+E_{d}^{\prime}+\left(X_{q}^{\prime}-X_{q}^{\prime \prime}\right) I_{q}\right]+\frac{X_{q}^{\prime \prime}-X_{l}}{X_{q}^{\prime}-X_{l}} \frac{d E_{d}^{\prime}}{d t}$

$\frac{d E_{q}^{\prime \prime}}{d t}=\frac{1}{T_{d}^{\prime \prime} 0}\left[-E_{q}^{\prime \prime}+E_{q}^{\prime}-\left(X_{d}^{\prime}-X_{d}^{\prime \prime}\right) I_{d}\right]+\frac{X_{d}^{\prime \prime}-X_{l}}{X_{d}^{\prime}-X_{l}} \frac{d E_{q}^{\prime}}{d t}$ 
$S A T=A \cdot e^{B\left|E_{q}^{\prime}\right|-C}$

$S A T_{d}=\frac{E_{q}^{\prime \prime}}{\left|E^{\prime \prime}\right|} S A T$

$S A T_{q}=-\frac{\left(X_{q}-X_{l}\right)}{\left(X_{d}-X_{l}\right)} \frac{E_{d}^{\prime \prime}}{\left|E^{\prime \prime}\right|} S A T$

Modelo \#6

$V_{d}=E_{d}^{\prime \prime}+X_{q}^{\prime \prime} I_{q}-R_{a} I_{d}$

$V_{q}=E_{q}^{\prime \prime}-X_{d}^{\prime \prime} I_{d}-R_{a} I_{q}$

$\frac{d E_{d}^{\prime \prime}}{d t}=\frac{1}{T_{q 0}^{\prime \prime}}\left[-E_{d}^{\prime \prime}+\left(X_{q}-X_{q}^{\prime \prime}\right) I_{q}\right]$

$\frac{d E_{q}^{\prime}}{d t}=\frac{1}{T_{d 0}^{\prime}}\left[E_{f d}+\frac{X_{d}-X_{d}^{\prime}}{X_{d}^{\prime}-X_{l}} E_{q}^{\prime \prime}-\frac{X_{d}-X_{l}}{X_{d}^{\prime}-X_{l}} E_{q}^{\prime}-\frac{\left(X_{d}-X_{d}^{\prime}\right)\left(X_{d}^{\prime \prime}-X_{l}\right)}{X_{d}^{\prime}-X_{l}} I_{d}-S A T\right]$

$\frac{d E_{q}^{\prime \prime}}{d t}=\frac{1}{T_{d 0}^{\prime \prime}}\left[-E_{q}^{\prime \prime}+E_{q}^{\prime}-\left(X_{d}^{\prime}-X_{d}^{\prime \prime}\right) I_{d}\right]+\frac{X_{d}^{\prime \prime}-X_{l}}{X_{d}^{\prime}-X_{l}} \frac{d E_{q}^{\prime}}{d t}$

$S A T=A \cdot e^{B\left|E_{q}^{\prime}\right|-C}$

\subsubsection{Modelagem das Cargas do Sistema}

Em um SEP as cargas são especificadas tipicamente pela potência complexa consumida. Sua representação não é uma tarefa trivial, já que elas podem ser de diversas naturezas (indutiva, capacitiva, resistiva) e possuir grande número de elementos não lineares em sua composição. Diferentes modelos podem ser utilizados para representá-las:

- Potência ativa e reativa constante;

- Corrente constante;

- Impedância constante (admitância constante); ou

- Qualquer combinação das três citadas acima. 
Em todas as representações parte-se de um valor de potência aparente (especificada) e de um valor de tensão que, dependendo do modelo empregado, pode ou não sofrer alterações durante o processo.

Para o presente estudo, será utilizado apenas o modelo de impedância constante. Com este objetivo as impedâncias das cargas são incluídas na matriz de admitância do sistema $Y_{B U S}$.

A fim de se representar as cargas por impedâncias constantes, faz-se uso da seguinte equação:

$$
Y_{n c a r g a}=\frac{\left(P_{n c a r g a}-j * Q_{n c a r g a}\right)}{V_{n}^{2}}
$$

onde

- $P_{\text {ncarga }}=$ potência ativa da carga ligada na barra $n$;

- $Q_{\text {ncarga }}=$ potência reativa da carga ligada na barra $n$;

- $V_{n}=$ módulo da tensão inicial na barra $n$;

- $Y_{\text {ncarga }}=$ representação da carga em admitância.

Após isso, $Y_{n c a r g a}$ é adicionada ao elemento $Y_{n n}$ da matriz de admitâncias do sistema.

\subsection{METODOLOGIA}

Como visto na Seção 4.2, o modelamento completo do SEP envolve equações algébricas e diferenciais. A simulação do comportamento dinâmico desse sistema, consiste na resolução simultânea no tempo do seguinte sistema de equações:

$$
\left\{\begin{array}{r}
\dot{\mathbf{x}}=\mathbf{f}(x, y, t) \\
0=\mathbf{g}(x, y, t)
\end{array}\right.
$$


em que $\mathbf{x}$ e $\mathbf{y}$ são os vetores que englobam as variáveis de estado diferenciais e algébricas, respectivamente.

A resolução do sistema 4.17 depende da forma como as duas equações serão relacionadas. Basicamente, existem dois métodos para a resolução do sistema, um alternado, onde cada uma das equações é resolvida separadamente durante cada passo de integração e um simultâneo quando o sistema é resolvido conjuntamente.

Neste trabalho, as equações do sistema 4.17 serão resolvidas simultaneamente. Isso será feito aplicando-se um método de integração numérica à parte diferencial do sistema, gerando assim expressões algébricas de variáveis discretas. Após essa etapa, o sistema como um todo é resolvido pelos métodos aplicáveis a sistemas não lineares, no caso, o método de Newton-Raphson como visto na seção 3.2.

Na figura 4.3 encontra-se representada a estrutura básica para o cálculo das variáveis por meio de métodos de integração numérica. Essa metodologia continua até que o tempo $t_{\max }$ seja atingido.

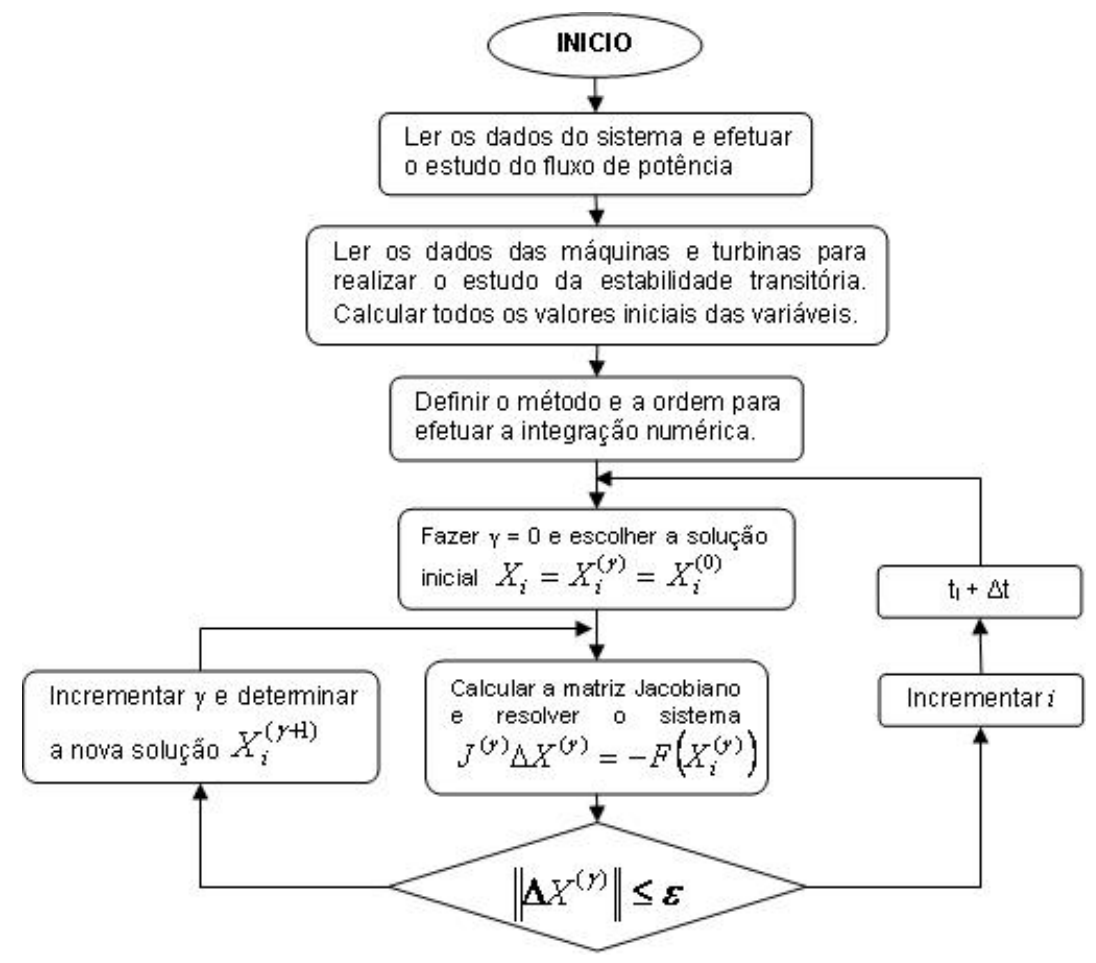

Figura 4.3: Estrutura básica para o cálculo das variáveis relativas ao problema de estabilidade transitória

No capítulo seguinte são mostrados os resultados de simulações. 


\section{Capítulo 5 SIMULAÇÃO}

\subsection{INTRODUÇÃO}

Para comprovar o efetivo funcionamento dos algoritmos desenvolvidos, foram realizadas simulações em dois tipos de circuitos. O primeiro se trata de um circuito que será denominado sistema teste I. O mesmo é formado por três barras. Já no segundo, denominado sistema teste II, se tem um SEP de nove barras, extraído de [7].

Neste capitulo serão apresentados os resultados de simulações para os diferentes modelos de geradores. Para o sistema teste I, foram utilizados os métodos de integração de Euler, Runge-Kutta e trapezoidal. Já para o sistema teste II foi utilizado apenas o método Trapezoidal Implícito, já que esse apresenta melhores características quanto a estabilidade numérica.

Posteriormente, são comparados os resultados obtidos em cada simulação, para assim analisar as vantagens e desvantagens de cada método.

\subsection{SISTEMA TESTE I}

Foi analisada a estabilidade transitória de uma estação de geração térmica, sistema formado por quatro geradores de 555 MVA, $24 \mathrm{kV}, 60 \mathrm{~Hz}$ ligados a uma barra infinita através de dois circuitos como mostrado na figura 5.1 [1].

As reatâncias do sistema mostradas na figura são dadas em pu e calculadas nas bases 2220 MVA, 24 kV (referenciado ao lado da linha de transmissão do transformador). Já as perdas resistivas foram desconsideradas neste exemplo. 


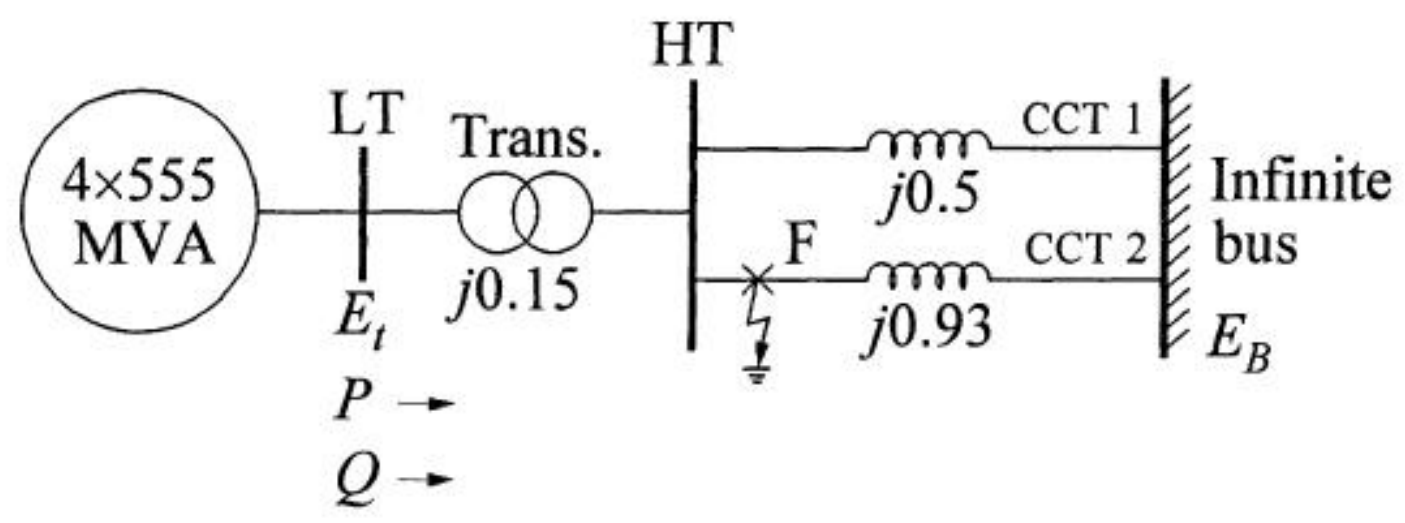

Figura 5.1: Sistema teste I

A condição inicial de operação, com quantidades expressas em $p u$ nas bases 2220 MVA e $24 \mathrm{kV}$, são as seguintes:

$$
\mathrm{P}=0.9 \quad \mathrm{Q}=0.436 \quad E_{t}=1 \angle 28.34^{\circ} \quad E_{B}=0.90081 \angle 0^{\circ}
$$

Para as simulações seguintes, foi considerado um curto-circuito trifásico no ponto $\mathrm{F}$ do circuito 2. Tal defeito será eliminado através da retirada desse circuito. O detalhamento da resolução numérica foi feito apenas para o método trapezoidal, sendo os gráficos gerados nas simulações utilizando-se os outros métodos abordados se encontram no apêndice A. Os geradores são modelados como um único equivalente sendo representado pelo modelo \#2 conforme equações 4.11. Os parâmetros do gerador, expressos em $p u$ são dados na tabela abaixo:

Tabela 5.1: Dados dos geradores do sistema de 3 barras

\begin{tabular}{cccccccc}
\hline$R a(\mathrm{pu})$ & $X d(\mathrm{pu})$ & $X q(\mathrm{pu})$ & $X^{\prime} d(\mathrm{pu})$ & $X^{\prime} q(\mathrm{pu})$ & $X p(\mathrm{pu})$ & $T^{\prime} d 0(s)$ & $H(s)$ \\
\hline 0 & 0.8 & 0.6 & 0.3 & 0.6 & 0.2 & 6 & 3.5 \\
\hline
\end{tabular}

Em relação aos outros métodos não será apresentada essa análise pormenorizada, sendo apresentadas somente as simulações e resultados, já que são análogos ao método exposto a seguir. 
Tendo em vista que a potência injetada no circuito pelo gerador é igual a $\overline{\mathbf{S}}_{\mathbf{G}}=0,9+$ $j * 0,436$ e que a tensão na barra 1 é de $\overline{\mathbf{V}}_{\mathbf{1}}=1 \angle 28,34^{\circ}$ temos, a partir do circuito:

$$
\overline{\mathbf{I}}_{\mathbf{G}}=\left(\frac{\overline{\mathbf{S}}_{\mathbf{G}}}{\overline{\mathbf{V}}_{\mathbf{1}}}\right)^{*}=\frac{0,9-j * 0,436}{1 \angle-28,34^{o}}
$$

Com esses dados, calcula-se a tensão interna do gerador:

$$
\begin{array}{r}
E \angle \delta=\overline{\mathbf{V}}_{\mathbf{1}}+j * X_{q} * \overline{\mathbf{I}}_{\mathbf{G}} \\
E \angle \delta=1,37 \angle 51,51^{\circ}
\end{array}
$$

Com isso e colocando a tensão da barra 1 e a corrente injetada pelo gerador em coordenadas retangulares, calculam-se as primeiras condições iniciais:

$$
\begin{aligned}
& \delta=51,51^{\circ}=0,8991 \mathrm{rad} \\
& V_{r 1}=0,88 \\
& V_{m 1}=0,4747 \\
& I_{r}=1 \\
& I_{m 1}=0,0435
\end{aligned}
$$

Para obtenção dos valores de tensão e corrente nos eixos $d$ e $q$, utiliza-se a transformação $\mathrm{r}-\mathrm{m} \rightarrow d-q:$

$$
\begin{aligned}
& {\left[\begin{array}{l}
V_{d 1} \\
V_{q 1}
\end{array}\right]=\left[\begin{array}{cc}
\sin \delta & -\cos \delta \\
\cos \delta & \sin \delta
\end{array}\right]\left[\begin{array}{c}
V_{r 1} \\
V_{m 1}
\end{array}\right]=\left[\begin{array}{l}
0,232 \\
0,972
\end{array}\right]} \\
& {\left[\begin{array}{l}
I_{d 1} \\
I_{q 1}
\end{array}\right]=\left[\begin{array}{cc}
\sin \delta & -\cos \delta \\
\cos \delta & \sin \delta
\end{array}\right]\left[\begin{array}{l}
I_{r 1} \\
I_{m 1}
\end{array}\right]=\left[\begin{array}{l}
0,634 \\
0,774
\end{array}\right]}
\end{aligned}
$$

A potência elétrica $P_{e}$ foi calculada a partir da fórmula abaixo, substituindo-se os valores de tensão e corrente antes da falta, para assim encontrar seu valor inicial. 


$$
P_{e}=V_{d} * I_{d}+V_{q} * I_{q}+R_{a} *\left(I_{G}^{2}\right)=0,9 p u
$$

Isolando $E_{d}^{\prime}$ e $E_{q}^{\prime}$ nas equações do modelo \#2 e subistituindo os resultados encontrados em (5.1) e (5.2), temos os seguintes resultados:

$$
\left[\begin{array}{c}
E_{d}^{\prime} \\
E_{q}^{\prime}
\end{array}\right]=\left[\begin{array}{l}
V_{d 1} \\
V_{q 1}
\end{array}\right]+\left[\begin{array}{cc}
R_{a} & -X_{q}^{\prime} \\
X_{d}^{\prime} & R_{a}
\end{array}\right]\left[\begin{array}{c}
I_{d 1} \\
I_{q 1}
\end{array}\right]=\left[\begin{array}{c}
0 \\
1,1458
\end{array}\right]
$$

Considerou-se o sistema com excitação constante. Assim, zerou-se a a derivada na equação (4.11), encontrando-se para $E_{f d}$ o valor abaixo (mantido constante durante toda a simulação):

$$
E_{f d}=\left(X_{d}-X_{d}^{\prime}\right) I_{d 1}+E_{q}^{\prime}=1,5233 p u
$$

Para calcular a tensão na barra 2, fez-se uso da lei dos nós.

$$
\begin{aligned}
& 0=\bar{Y}_{21} * \bar{V}_{1}+\bar{Y}_{22} * \bar{V}_{2}+\bar{Y}_{23} * V_{i n f} \\
& \bar{V}_{2}=0,887+j 0,325
\end{aligned}
$$

A análise depende de variáveis algébricas e variáveis diferenciais, listadas a seguir nas matrizes $\mathrm{X}$ (variáveis de estado) e $\mathrm{Y}$ (variáveis algébricas):

$$
\begin{aligned}
& X=\left[\begin{array}{lll}
\Delta \omega & \delta & E_{q}^{\prime}
\end{array}\right]^{T} \\
& Y=\left[\begin{array}{lllllllllll}
I_{r 1} & I_{m 1} & I_{d 1} & I_{q 1} & V_{r 1} & V_{m 1} & V_{r 2} & V_{m 2} & V_{d 1} & V_{q 1} & P_{e}
\end{array}\right]^{T}
\end{aligned}
$$

Para as equações diferenciais foi aplicado o método trapezoidal e em seguida, solucionadas pelo método de Newton-Raphson. 
A partir dos resultados encontrados, expõe-se as simulações obtidas tendo em vista que estes foram inseridos em um programa desenvolvido em MATLAB para cálculo iterativo das possíveis soluções.

Pode-se verificar na Fig. 5.2 a interface gráfica da simulação gerada a partir dos resultados obtidos, como comentado anteriormente.

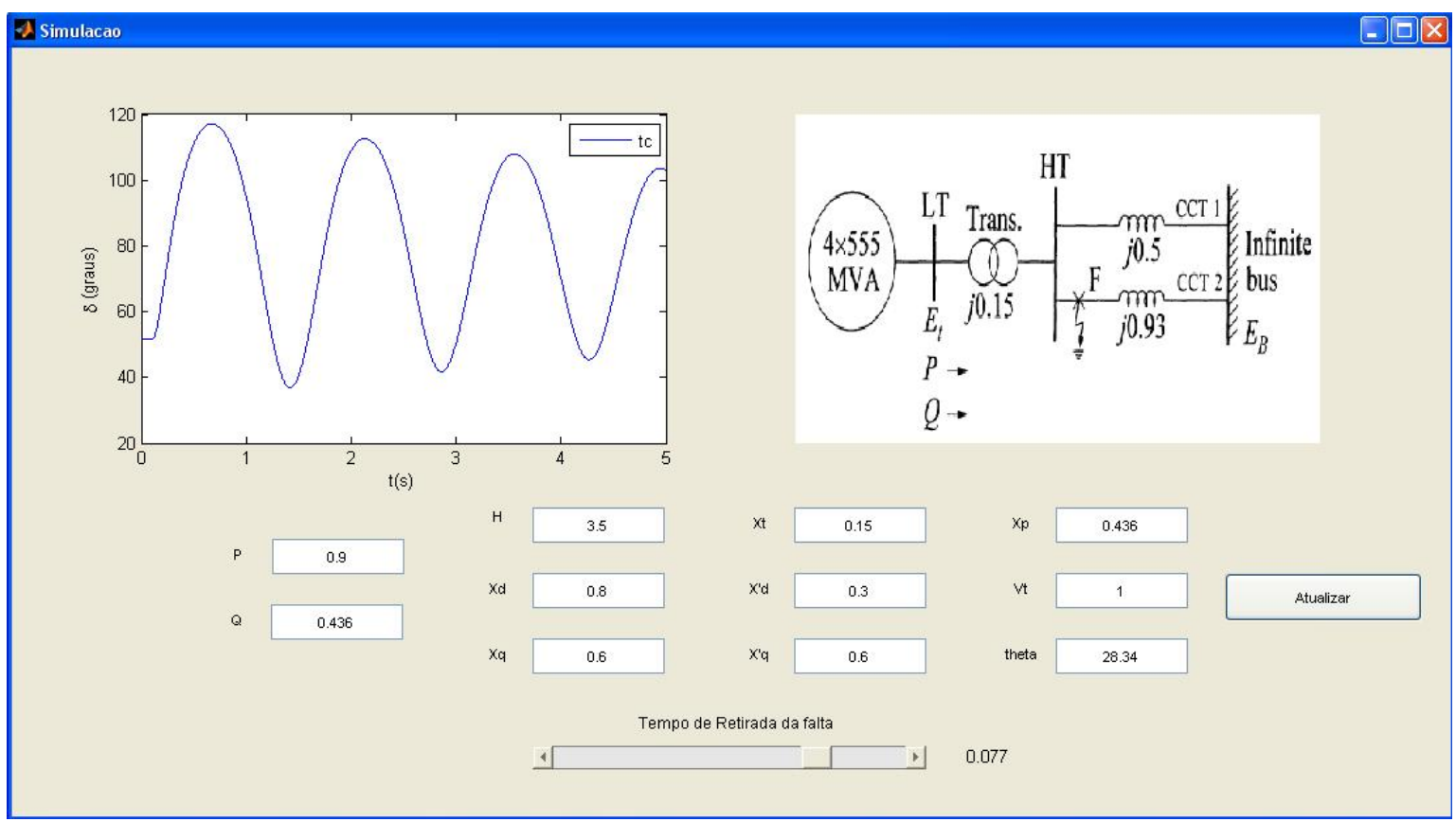

Figura 5.2: Interface gráfica simulação.

Nela verifica-se o gráfico do ângulo do rotor em função do tempo. O passo de integração foi $0,005 \mathrm{~s}$; o tempo total de simulação foi de $5 \mathrm{~s}$ e o tempo de abertura do circuito 2 foi de $0,077 \mathrm{~s}$, como mostrado na figura 5.2. Nessa figura, o gráfico mostra que $\delta$ oscila em torno de um ponto de equilíbrio indicando que a falta foi retirada antes que o sistema perdesse a estabilidade.

As figuras 5.3 e 5.4 mostram a resposta do sistema para dois tempos de retirada da falta diferentes.

Importante notar que o tempo de retirada de falta é um parâmetro essencial para a determinação da estabilidade transitória de sistema. Ainda na Fig. 5.2 é apresentada a representação do sistema no período pré-falta e os dados do gerador, conforme tabela 5.1 . 


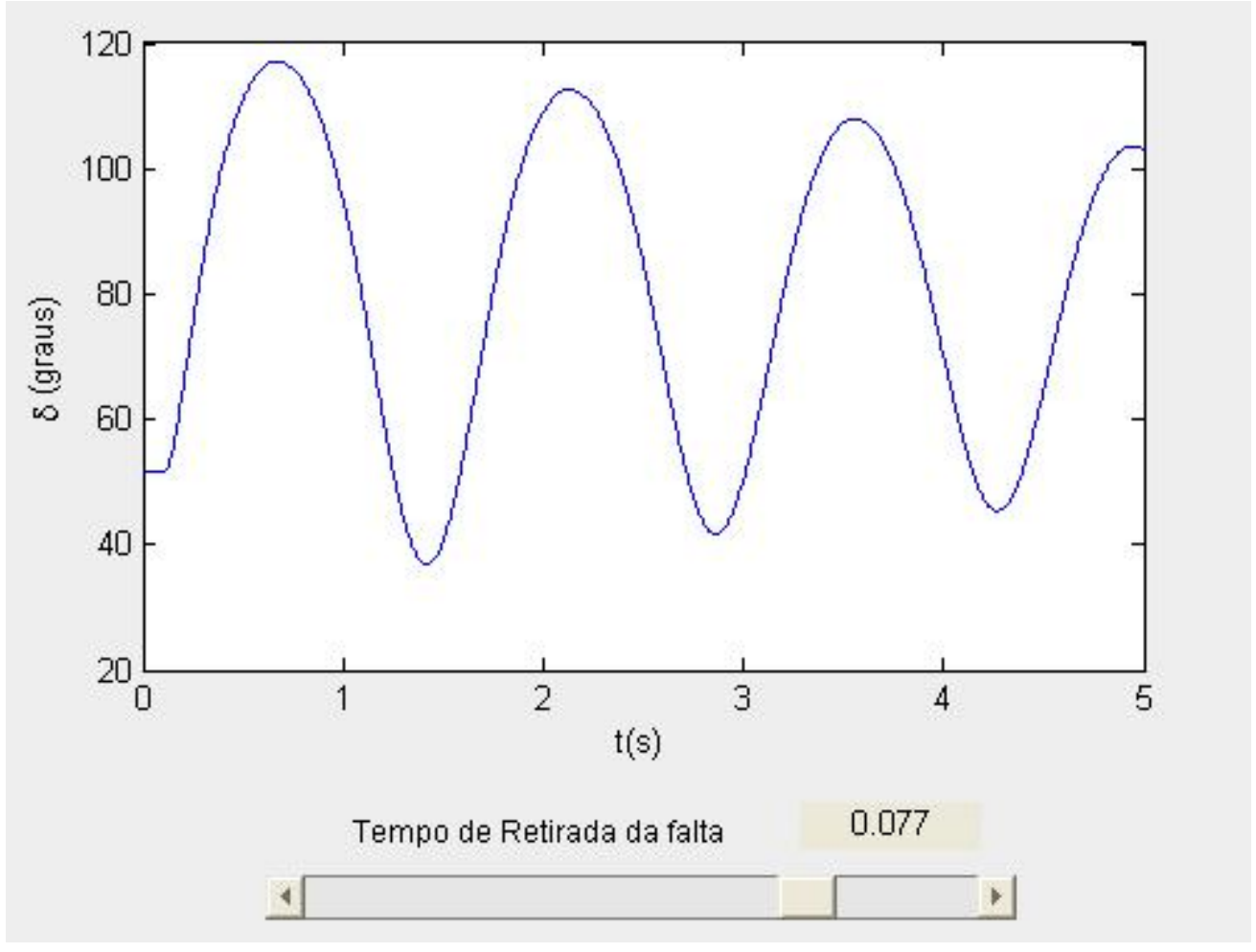

Figura 5.3: Ângulo do rotor - tempo máximo para estabilidade.

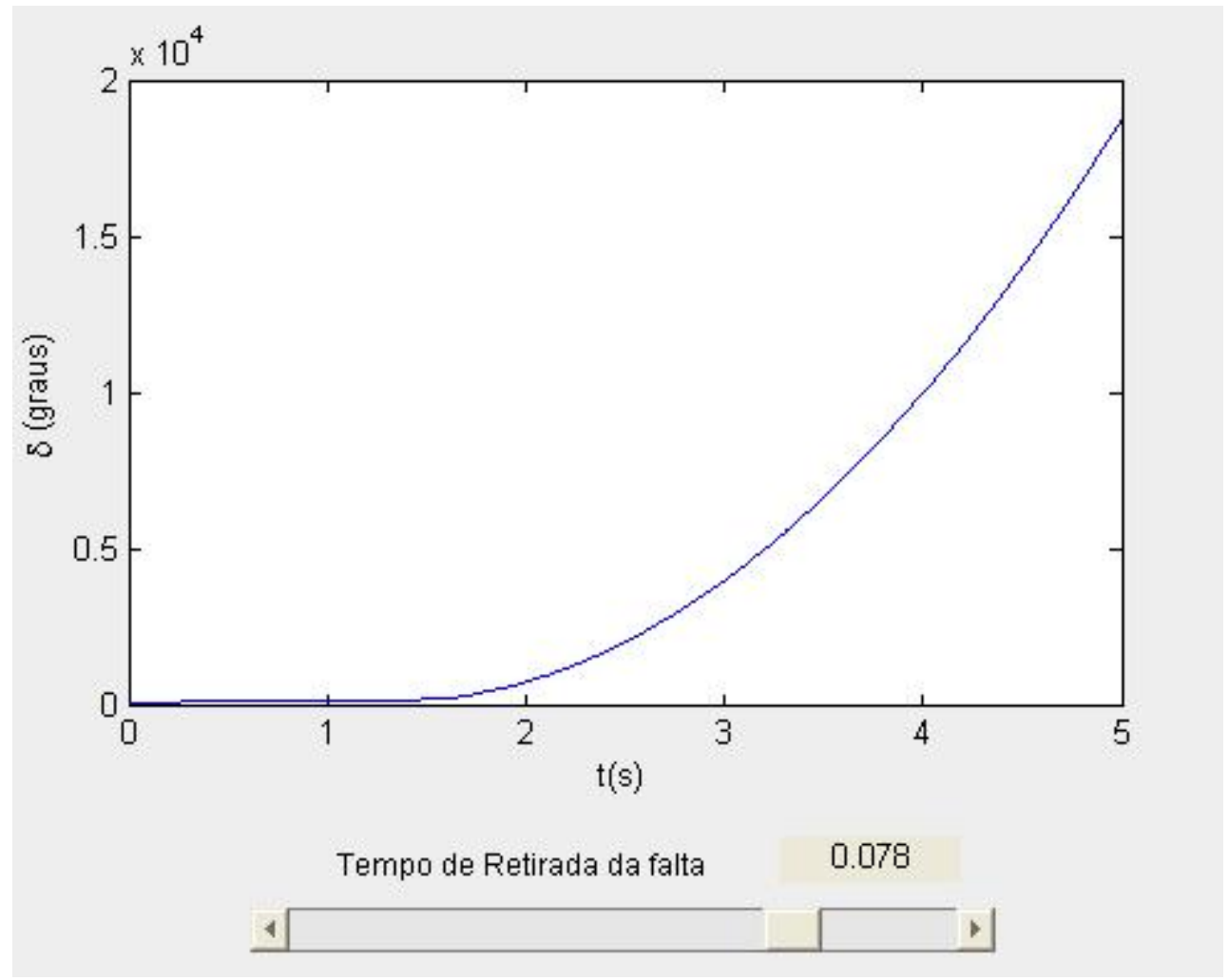

Figura 5.4: Ângulo do rotor - Tempo mínimo para instabilidade. 


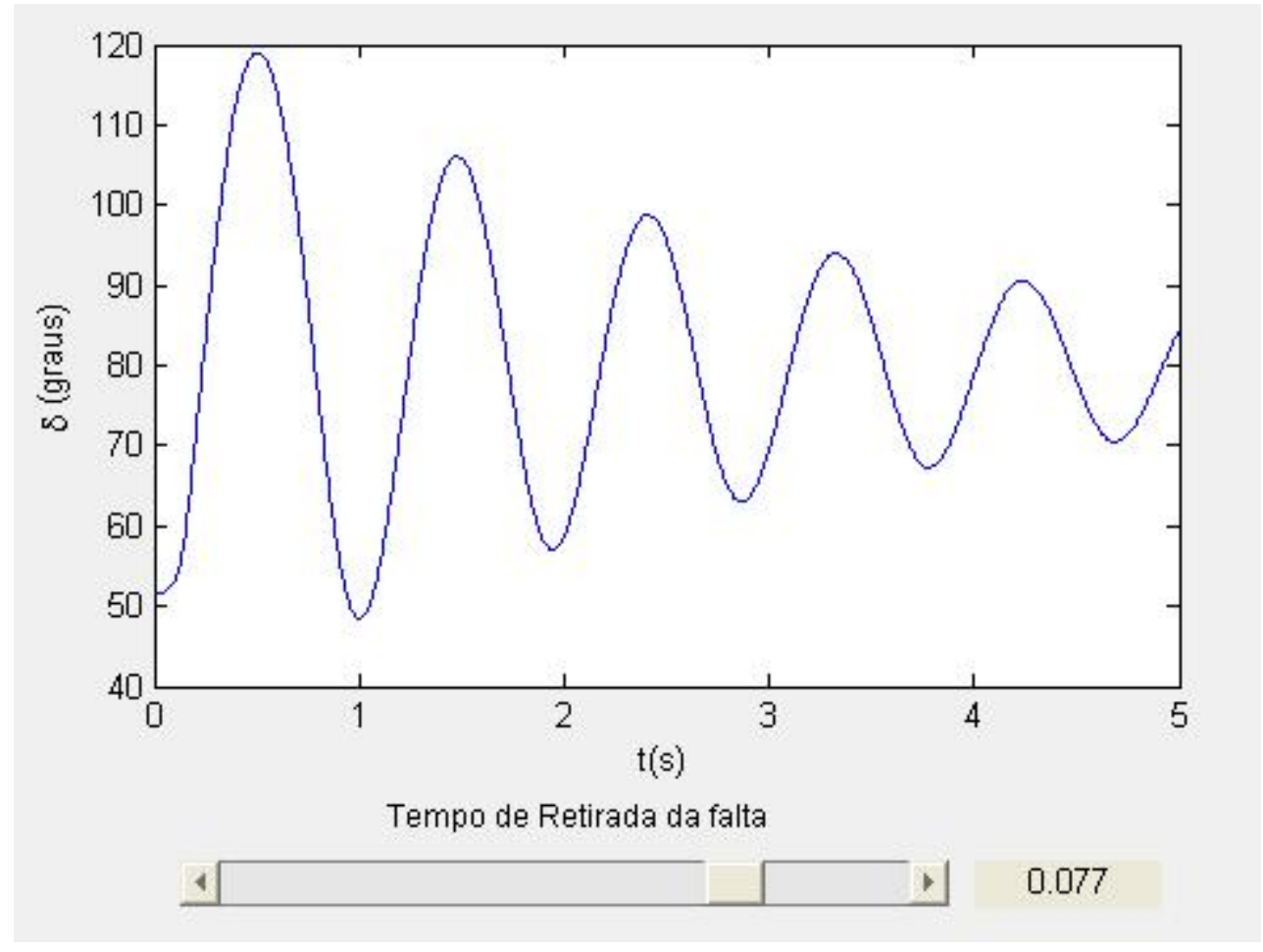

Figura 5.5: Resultado da simulação para o modelo \#6

Variando-se a duração da falta, pode-se analisar o tempo máximo de abertura do circuito 2 que garante a estabilidade do sistema, $t_{c}$. Na figura 5.3 é apresentado exatamente esse tempo.

De maneira análoga, o resultado obtido para um tempo de retirada de falta superior a $t_{c}$ é verificado na figura 5.4. Conforme dito anteriormente, o sistema perde o sincronismo quando ocorre demora na retirada do curto-circuito, sendo $0,077 \mathrm{~s}$ o máximo tempo para a manutenção da estabilidade.

Verificou-se portanto a análise básica de um sistema em falha e o tempo crítico para se retirar a falha antes que o sistema se tornasse instável. Estendeu-se o estudo para outros métodos, estes expostos a seguir.

Afigura 5.5 mostra o resultado do ângulo $\delta$ do rotor para o caso em estudo, porém utilizando o modelo de gerador \#6 do Pacdyn.

Comparando os gráficos 5.3 e 5.5 para o mesmo tempo de falta, percebe-se que o ângulo do rotor comporta-se de maneira distinta. Isso se deve a um maior 


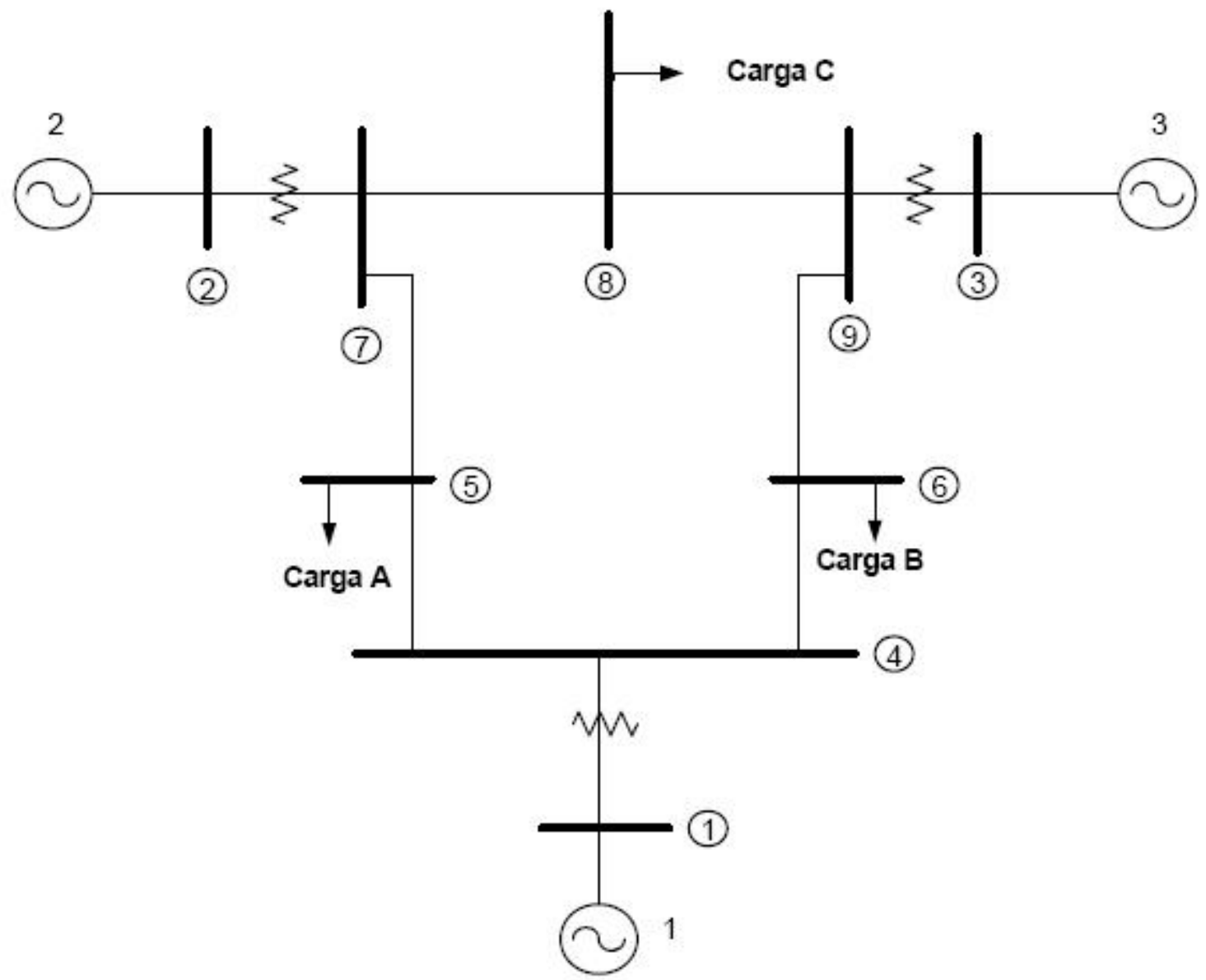

Figura 5.6: Circuito de 9 barras e 3 geradores [7]

amortecimento encontrado no modelo \#6 já que ele leva em conta efeitos de enrolamentos amortecedores.

No Apêndice A pode ser encontrado os resultados das simulações obtidas para os demais métodos de integração e outros modelos.

\subsection{SISTEMA TESTE II- 9 BARRAS E 3 MÁQUINAS SÍNCRONAS}

Nesse caso foram realizadas simulações com um sistema de nove barras e três geradores [7]. O diagrama unifilar do sistema é apresentado na figura abaixo:

Para obter o resultado do fluxo de potência do sistema é necessário se ter os dados das interligações e das barras. Tais dados são apresentados nas tabelas 5.2, 5.3 e 5.4. 
A partir daí, o programa MATPOWER@ realiza o cálculo do fluxo de carga, gerando os dados apresentados na tabela 5.5. Os dados dos geradores são mostrados na tabela 5.6.

Tabela 5.2: Dados de ligação-Linhas de Transmissão

\begin{tabular}{|cc|c|c|c|c|}
\hline \hline \multicolumn{5}{c}{ LinHA DE TRANSMiss ̃̃o } \\
\hline \multirow{2}{*}{ de para } & Resistência & Reatância & Capacitância & Comprimento \\
\cline { 3 - 6 } & $(\mathrm{ohm} / \mathrm{km})$ & $(\mathrm{ohm} / \mathrm{km})$ & $(\mathrm{nF} / \mathrm{km})$ & $(\mathrm{km})$ \\
\hline 7 & 8 & 0.0749 & 0.6348 & 6.220 & 60.0 \\
8 & 9 & 0.0630 & 0.5332 & 5.240 & 100.0 \\
7 & 5 & 0.0677 & 0.3407 & 3.068 & 250.0 \\
5 & 4 & 0.0529 & 0.4496 & 4.412 & 100.0 \\
4 & 6 & 0.0600 & 0.3200 & 2.640 & 150.0 \\
6 & 9 & 0.0688 & 0.2998 & 2.640 & 300.0 \\
\hline \hline
\end{tabular}

Tabela 5.3: Dados de ligação-Transformadores

\begin{tabular}{|cc|c|c|c|}
\hline \multicolumn{5}{c}{ Transformador } \\
\hline \multirow{2}{*}{ de para } & \multirow{4}{*}{ para } & Resistência & Reatância & $\mathbf{S}_{\mathbf{n}}$ \\
\cline { 3 - 5 } & & $(\mathrm{pu})$ & $(\mathrm{pu})$ & $(\mathrm{MVA})$ \\
\hline 1 & 4 & 0.0000 & 0.0576 & 100 \\
2 & 7 & 0.0000 & 0.0625 & 100 \\
3 & 9 & 0.0000 & 0.0586 & 100 \\
\hline \hline
\end{tabular}


Tabela 5.4: Dados de barra

\begin{tabular}{|c|c|c|c|l|l|l|}
\hline \hline \multirow{2}{*}{ Número } & \multirow{2}{*}{ Nome } & \multirow{2}{*}{ Tipo } & Tensão & $\begin{array}{l}\text { P.Ativa } \\
\text { gerada }\end{array}$ & $\begin{array}{l}\text { P.Ativa } \\
\text { carga }\end{array}$ & $\begin{array}{l}\text { P.Reativa } \\
\text { carga }\end{array}$ \\
\cline { 4 - 7 } & & $\mathbf{( k V )}$ & $\mathbf{( p u )}$ & $\mathbf{( p u )}$ & $\mathbf{( p u )}$ \\
\hline 1 & gerador 1 & 3 & 16.500 & 0.000 & 0.000 & 0.000 \\
2 & gerador 2 & 2 & 18.000 & 1.630 & 0.000 & 0.000 \\
3 & gerador 3 & 2 & 13.800 & 0.850 & 0.000 & 0.000 \\
4 & alfa & 1 & 230.000 & 0.000 & 0.000 & 0.000 \\
5 & beta & 1 & 230.000 & 0.000 & -1.250 & -0.500 \\
6 & gama & 1 & 230.000 & 0.000 & -0.900 & -0.300 \\
7 & delta & 1 & 230.000 & 0.000 & 0.000 & 0.000 \\
8 & eta & 1 & 230.000 & 0.000 & -1.000 & -0.350 \\
9 & lambda & 1 & 230.000 & 0.000 & 0.000 & 0.000 \\
\hline \hline
\end{tabular}

Tabela 5.5: Resultados do Fluxo de carga

\begin{tabular}{|c|c|c|c|c|c|c|c|c|}
\hline \multirow{3}{*}{ Número } & \multirow{3}{*}{ Nome } & \multirow{3}{*}{ Tipo } & \multicolumn{2}{|c|}{ Tensão } & \multicolumn{2}{|c|}{ Geração } & \multicolumn{2}{|c|}{ Carga } \\
\hline & & & (Módulo) & (Ângulo) & (Ativo) & (Reativo) & (Ativo) & (Reativo) \\
\hline & & & $(\mathrm{pu})$ & (graus) & $(\mathrm{pu})$ & $(\mathrm{pu})$ & $(\mathrm{pu})$ & $(\mathrm{pu})$ \\
\hline 1 & gerador 1 & 3 & 1.040 & 0.00 & 0.716 & 0.271 & 0.000 & 0.000 \\
\hline 2 & gerador 2 & 2 & 1.025 & 9.29 & 1.630 & 0.067 & 0.000 & 0.000 \\
\hline 3 & gerador 3 & 2 & 1.025 & 4.68 & 0.850 & -0.109 & 0.000 & 0.000 \\
\hline 4 & alfa & 1 & 1.026 & -2.22 & 0.000 & 0.000 & 0.000 & 0.000 \\
\hline 5 & beta & 1 & 0.996 & -3.98 & 0.000 & 0.000 & 1.250 & 0.500 \\
\hline 6 & gama & 1 & 1.013 & -3.67 & 0.000 & 0.000 & 0.900 & 0.300 \\
\hline 7 & delta & 1 & 1.026 & 3.73 & 0.000 & 0.000 & 0.000 & 0.000 \\
\hline 8 & eta & 1 & 1.016 & 0.74 & 0.000 & 0.000 & 1.000 & 0.350 \\
\hline 9 & lambda & 1 & 1.032 & 1.98 & 0.000 & 0.000 & 0.000 & 0.000 \\
\hline
\end{tabular}

Foram consideradas simulações para três tipos de falta: 
Tabela 5.6: Dados dos geradores

\begin{tabular}{|l|c|c|c|}
\hline \hline Gerador & 1 & 2 & 3 \\
\hline $\mathbf{S}_{\mathbf{n}}(\mathbf{M V A})$ & 100 & 100 & 100 \\
\hline $\mathbf{X}_{\mathbf{d}}(\mathbf{p u})$ & 0,14 & 0,89 & 1,31 \\
\hline $\mathbf{X}_{\mathbf{d}}^{\prime} \mathbf{( p u )}$ & 0,06 & 0,11 & 0,18 \\
\hline $\mathbf{X}_{\mathbf{q}}(\mathbf{p u})$ & 0,969 & 0,864 & 1,250 \\
\hline $\mathbf{X}_{\mathbf{q}}^{\prime}(\mathbf{p u})$ & 0,09 & 0,19 & 0,25 \\
\hline $\mathbf{X}_{\mathbf{p}}(\mathbf{p u})$ & 0,2 & 0,2 & 0,2 \\
\hline $\mathbf{T}_{\mathbf{d} \mathbf{0}}^{\prime}$ & 8,96 & 6,00 & 5,89 \\
\hline $\mathbf{R}_{\mathbf{a}}(\mathbf{p u})$ & 0 & 0 & 0 \\
\hline $\mathbf{H}(\mathbf{s})$ & 23,64 & 6,40 & 3,10 \\
\hline \hline
\end{tabular}

- Distúrbio na potência mecânica de entrada em um gerador;

- Curto-circuito trifásico em uma barra, com eliminação do curto sem retirada de linha;

- Curto-circuito trifásico em uma barra, havendo desligamento permanente de uma linha após eliminação da falta.

Os três tipos de simulações de falta foram realizados utilizando-se um passo de integração de 0,001 s e um tempo máximo de simulação de $3 \mathrm{~s}$. O modelo de gerador adotado para estas simulações é o \#2.

\subsubsection{Distúrbio na Potência Mecânica do gerador 2}

Para esta simulação, será considerado um aumento de $5 \%$ na potência mecânica $P_{m}$ no gerador 2 do sistema. Tal incremento, é aplicado em $t=0,3 s$ e será retirado em $t=0.5 \mathrm{~s}$, logo, a duração da perturbação é de $\Delta t=0,2 \mathrm{~s}$. A figura 5.7 mostra os ângulos absolutos do rotor devido à perturbação. A figura 5.8 mostra os ângulos dos geradores 2 e 3 em relação ao ângulo do rotor do gerador 1 . 


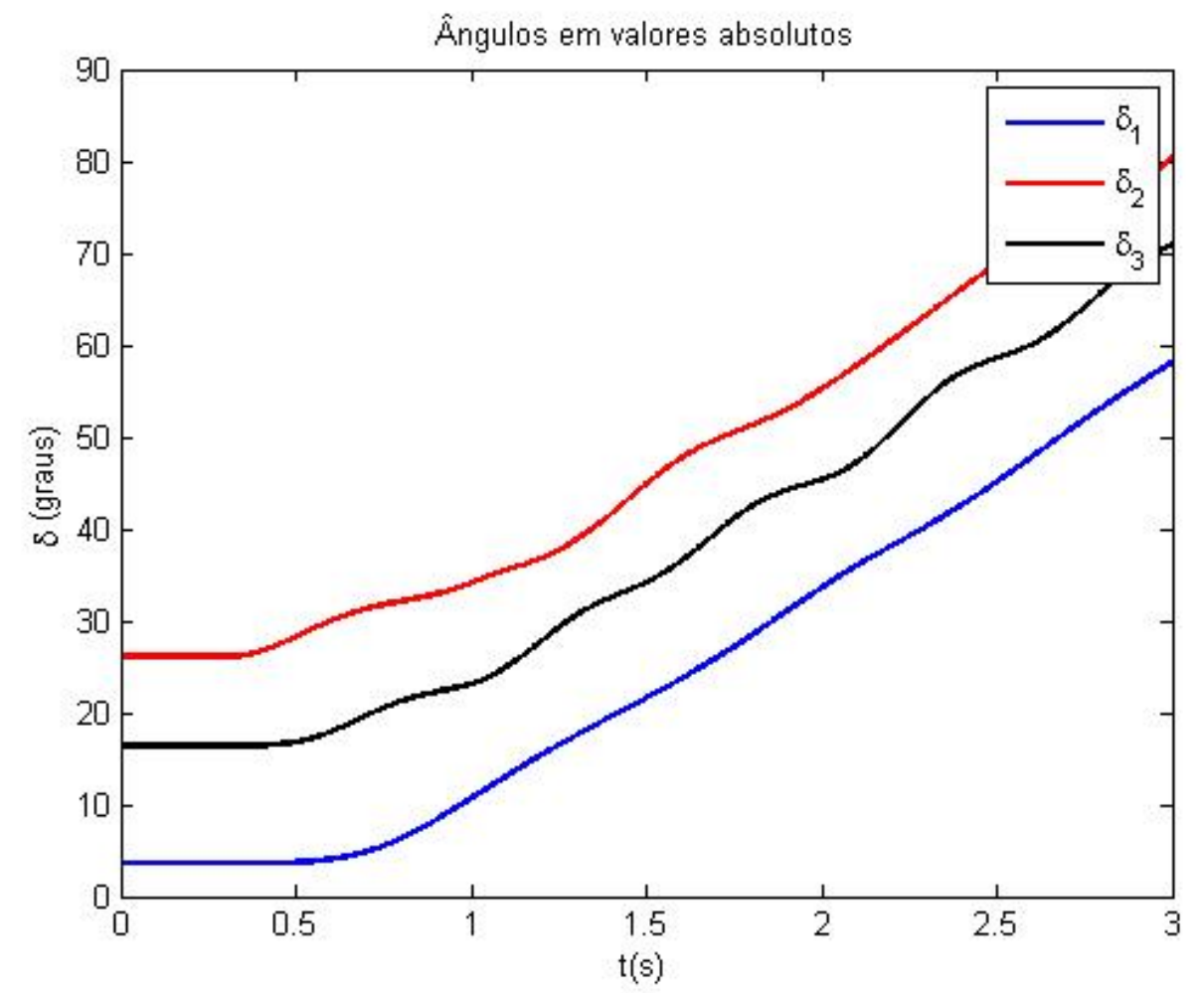

Figura 5.7: Resposta de $\delta$, em valor absoluto, a uma perturbação em $P_{m}$

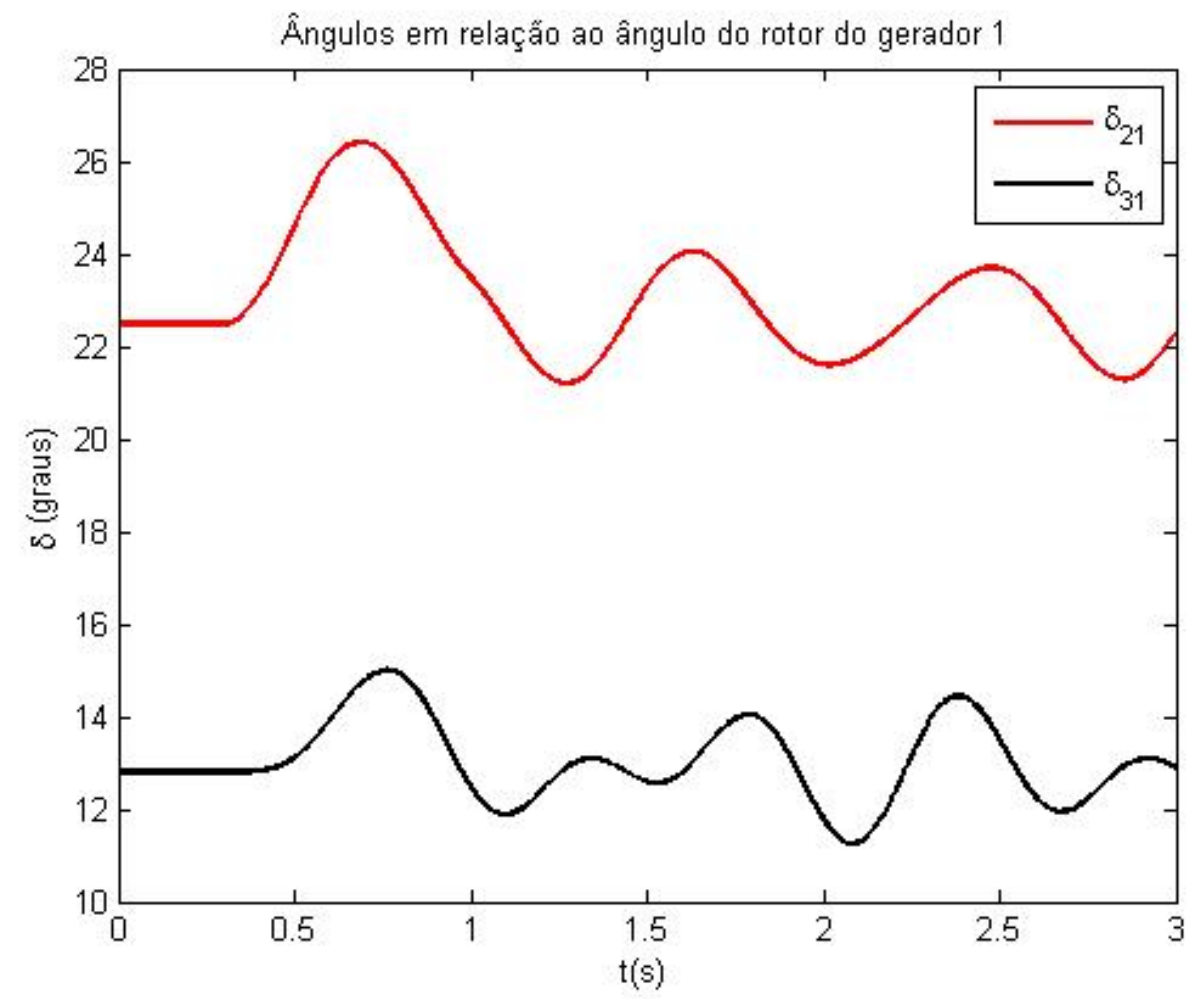

Figura 5.8: Resposta de $\delta$ a uma perturbação em $P_{m}$, referenciado ao gerador 1 
A análise das defasagens angulares é feita considerando, empiricamente, como ângulo limite $180^{\circ}$ entre as máquinas em estudo e uma máquina de referência [5]. desta forma, se a defasagem angular dos geradores 2 e 3 em relação ao gerador 1 for maior que $180^{\circ}$, o sistema é considerado instável. Da figura, pode-se concluir que o sistema permanece estável para a dada perturbação.

Quando a potência mecânica do gerador é incrementada, o torque mecânico fica maior que o elétrico e, consequentemente há aceleração do rotor e um aumento na defasagem dos ângulos dos geradores. Ao atingir o novo ponto de equilíbrio, a potência mecânica se iguala novamente à elétrica, porém, devido à inércia das massas do gerador, o ângulo de defasagem continua a aumentar. Dessa forma, a potência elétrica supera a mecânica e ocorre frenagem no rotor, diminuindo $\omega_{r}$ e, em seguida, $\delta$. Novamente devido a inércia, o gerador não permanece no ponto de equilíbrio e sua potência mecânica supera a elétrica e o ciclo se reinicia. Essa dinâmica na qual o ângulo do rotor oscila em torno de um novo ponto de equilíbrio é simbolizada pelo período de $t=0,3 \mathrm{~s}$ a $0,5 \mathrm{~s}$ do gráfico da figura 5.8. Terminado esse período, o ângulo de cada gerador continua a oscilar, porém em torno do antigo ponto de equilíbrio.

\subsubsection{Curto-circuito Trifásico na barra 7 sem desligamento da linha}

Nesta simulação, é considerado um curto-circuito trifásico próximo à barra 7 do sistema. Essa falta ocorre em $t=0,3 \mathrm{~s}$ e cessa em $t=0,5 \mathrm{~s}$. Não há retirada da linha em falta, logo a matriz de admitância do sistema permanece idêntica à do período pré-falta. A resposta dos ângulos do rotor de cada gerador é mostrada no gráfico da figura 5.9. Já a defasagem angular calculada com referência ao gerador 1 é mostrada no gráfico da figura 5.10. 


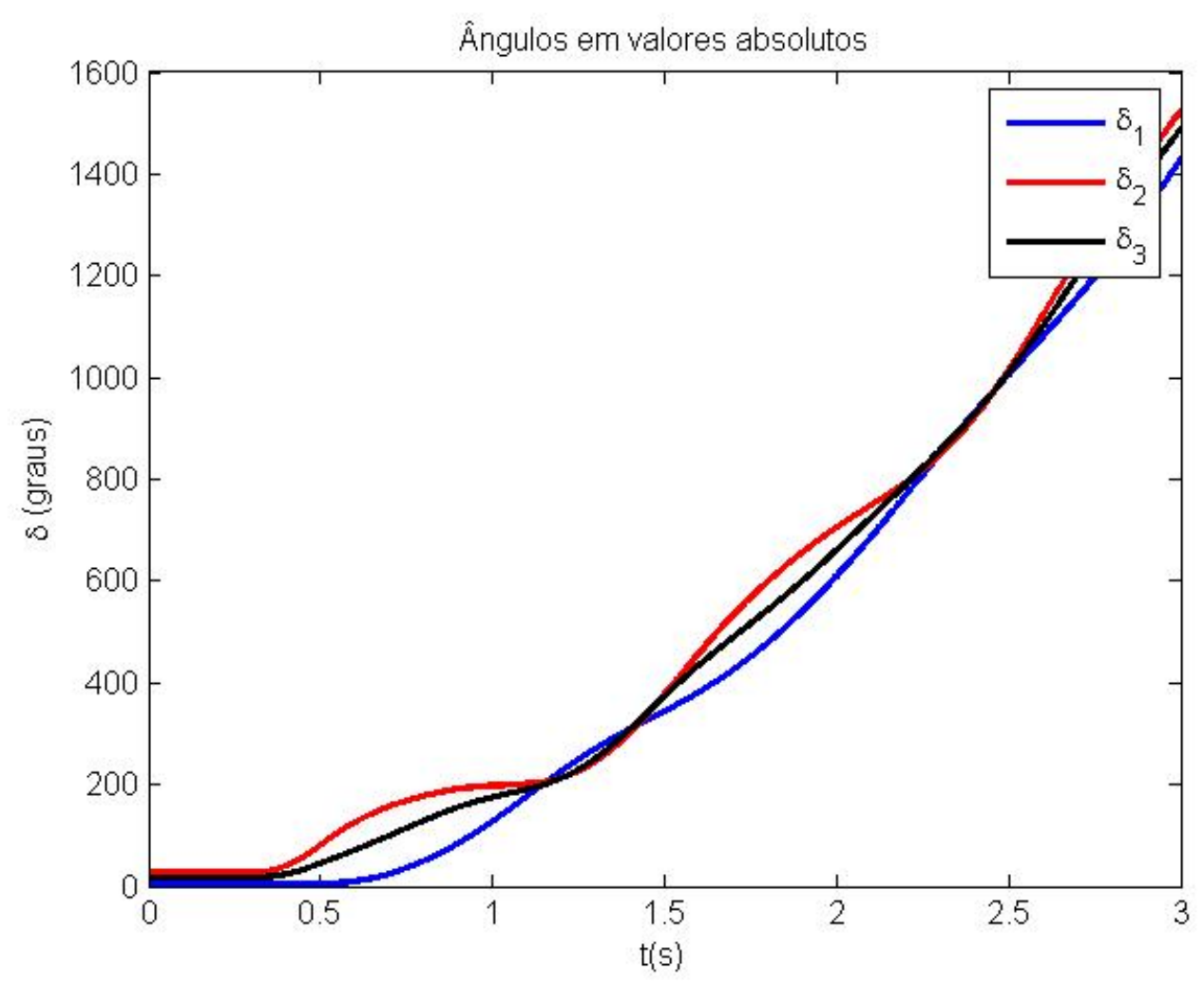

Figura 5.9: Resposta de $\delta$ a um curto na barra 7, em valor absoluto

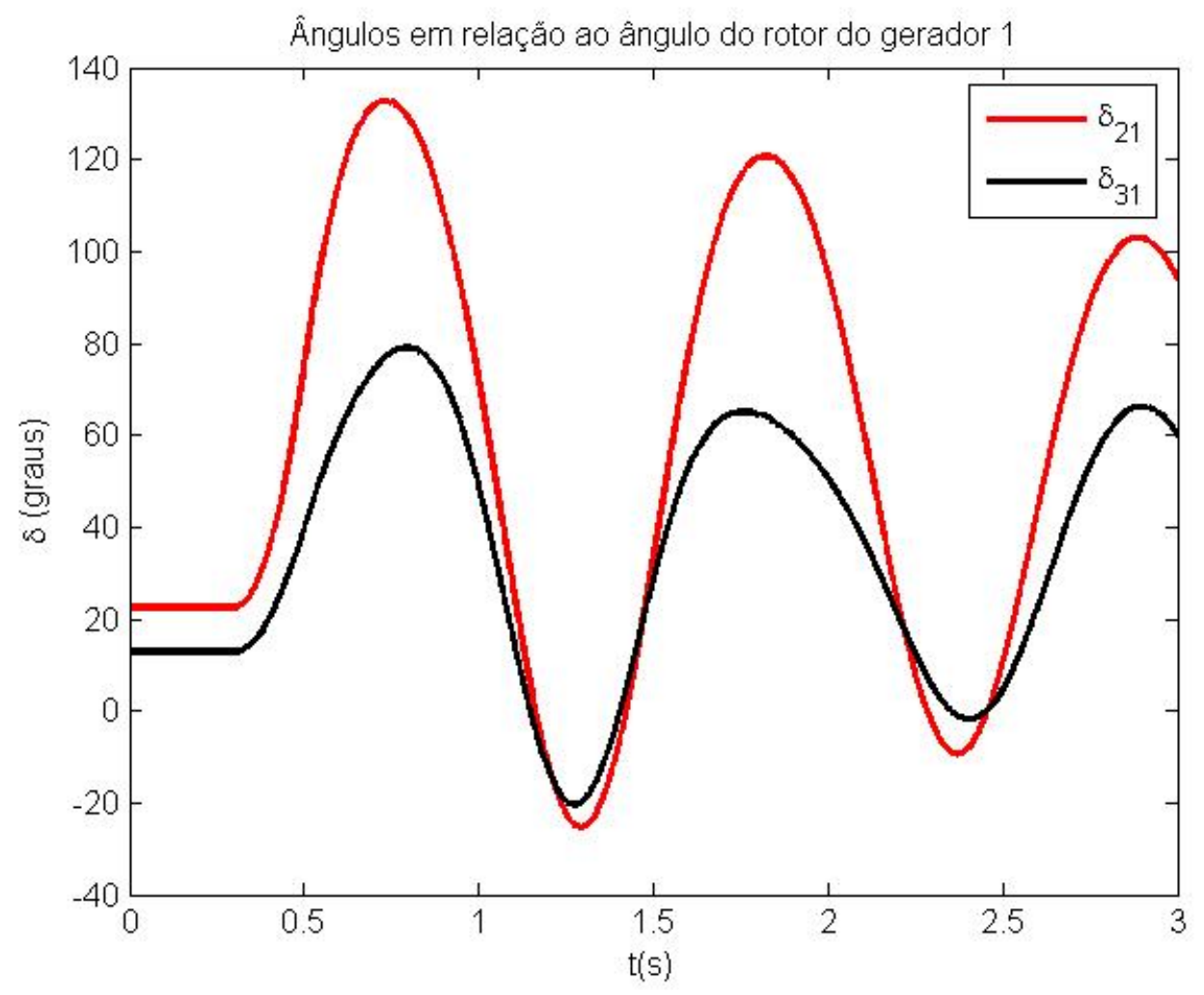

Figura 5.10: Resposta de $\delta$ a um curto na barra 7 , relativo ao gerador 1 
Percebe-se da figura 5.10 que o ângulo $\delta$ dos geradores 2 e 3 varia senoidalmente em relação ao gerador 1, porém tal variação não caracteriza perda de sincronismo, se mantendo dentro dos limites de estabilidade.

\subsubsection{Curto-circuito Trifásico na barra 7 com desligamento de linha}

Para esta simulação, será considerado um curto-circuito trifásico na barra 7 do sistema. Esse defeito é eliminado com a retirada da linha que interliga os barramentos 5 e 7 . O curto persiste por $\Delta t=0.2 \mathrm{~s}$ e tem início em $t=0,3 \mathrm{~s}$. Quando $t=0,5 \mathrm{~s}$, os disjuntores da linha que interliga as barras 5 e 7 atuam, retirando o curto-circuito que ocasionou a falta. As figuras 5.11 e 5.12 mostram o comportamento dos ângulos dos geradores em função do tempo.

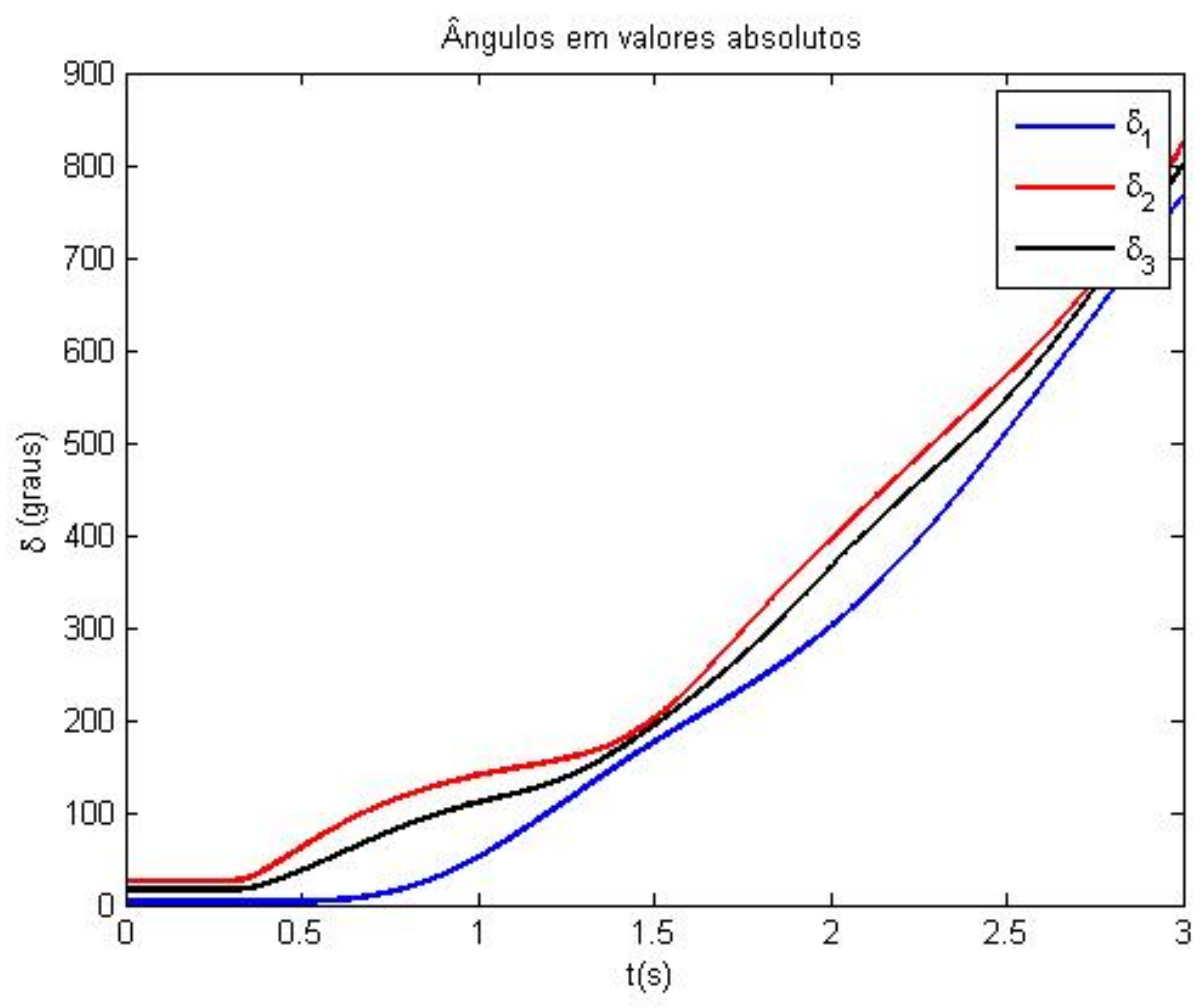

Figura 5.11: Curva $\delta x t$ para um curto na barra 7, com retirada da linha 5-7

As figuras 5.11 e 5.12 nos mostram que os geradores se mantém síncronos para a falta apresentada. 


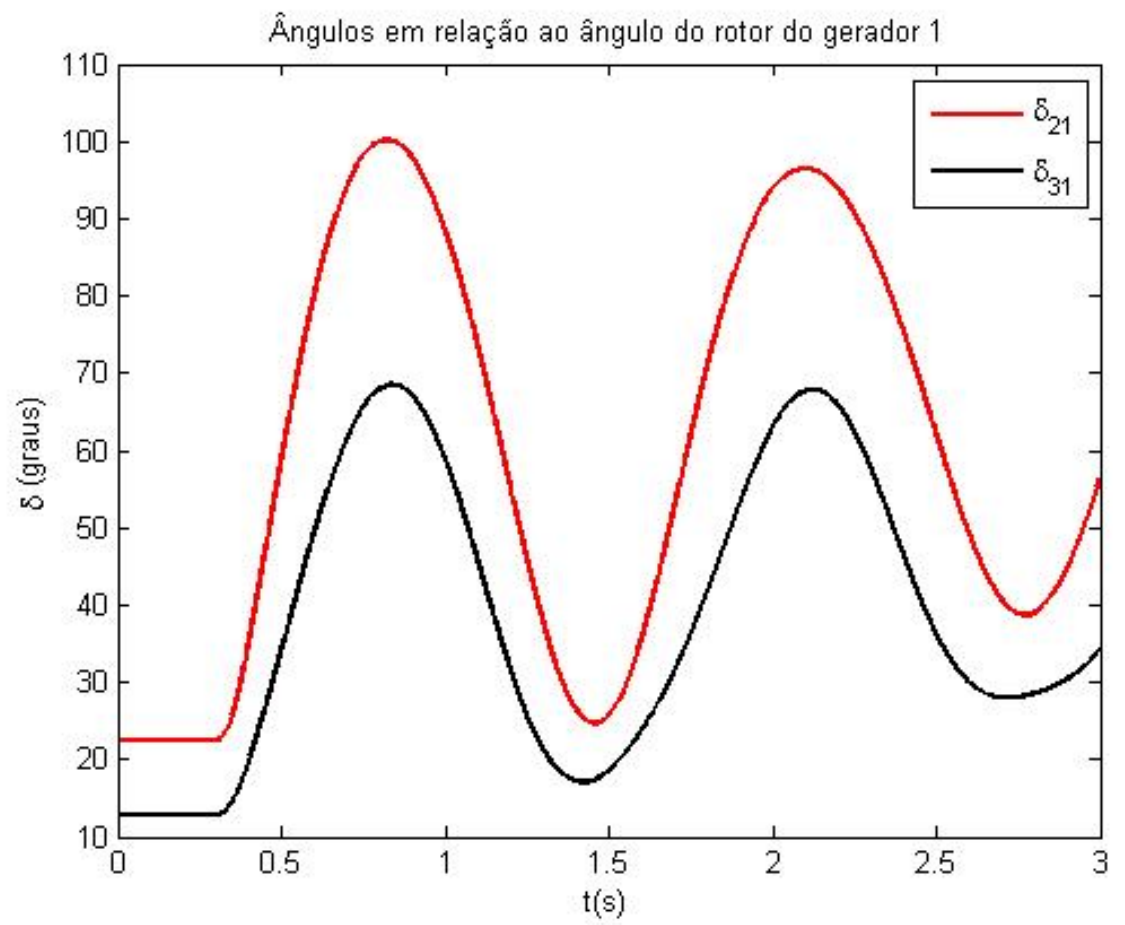

Figura 5.12: Defasagem angular para um curto na barra 7, com retirada da linha 5-7

\subsubsection{Correção do defeito após o tempo crítico}

As simulações anteriores foram feitas para um tempo de falta de 0,2s. Agora, será avaliado como o sistema se comportaria caso o tempo de remoção da falta fosse superior. Com esse objetvo em mente, foram efetuadas outras simulações com uma duração maior para o defeito, tendo-se outras curvas do ângulo do rotor para a defasagem angular relativa ao gerador 1 .

A figura 5.13 mostra a variação do rotor dos geradores ao serem submetidos a uma variação na potência mecânica durante um intervalo de tempo elevado, considerandose os períodos de tempo analizados nos estudos de estabilidade transitória.

A figura 5.14 mostra que tanto o ângulo $\delta_{21}$ e $\delta_{31}$ crescem indefinidamente, caracterizando instabilidade do SEP.

De acordo com o gráfico da figura 5.15, a ativação dos disjuntores foi tardia e não foi possível impedir a perda do sincronismo entre os geradores. Percebe-se também, 


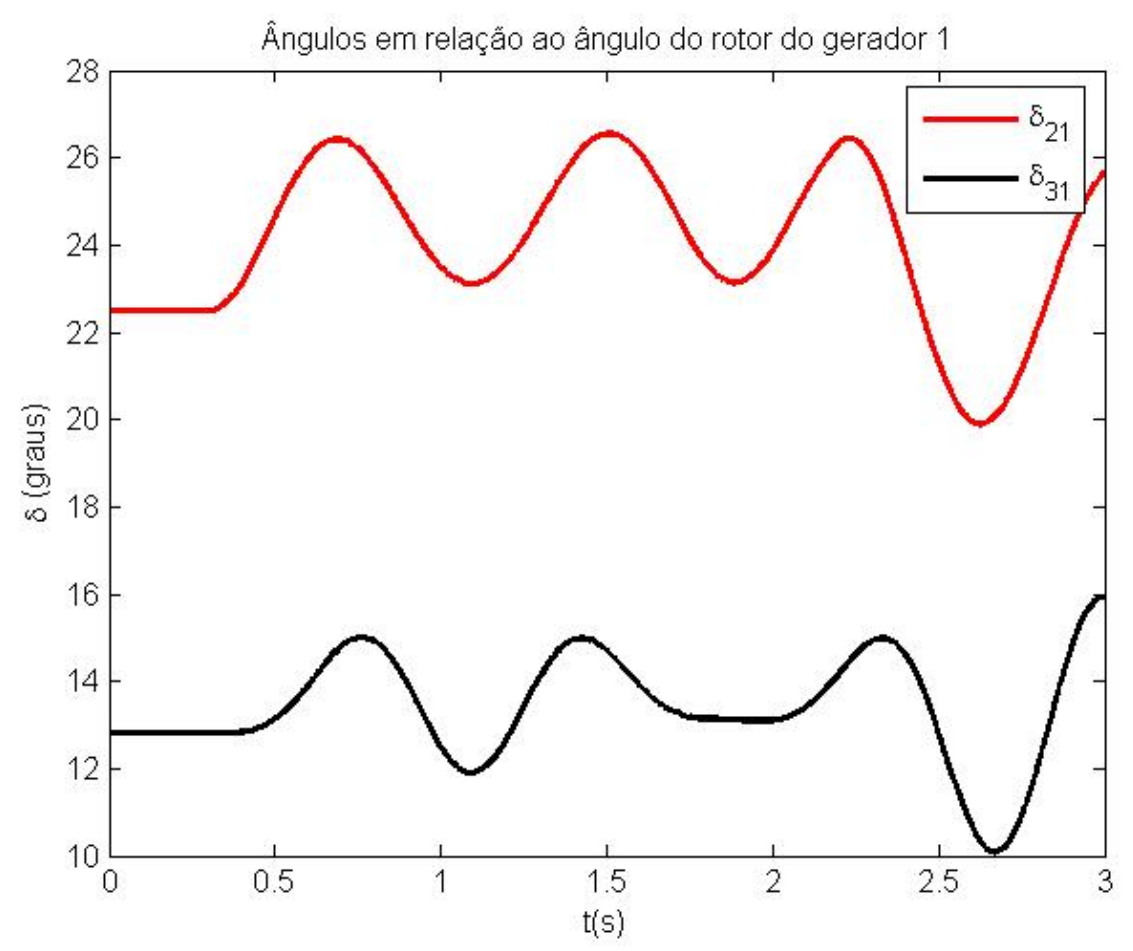

Figura 5.13: Resposta de $\delta$ a uma perturbação em $P_{m}, t_{\text {falta }}=2,2 \mathrm{~s}$

que o gerador 2 diverge mais rapidamente, o que já era esperado, tendo em vista sua proximidade do curto.

Além destas, foram feitas várias outras simulações variando-se o tempo de retirada da falta. Estas simulações permitem obter as seguintes conclusões:

* Para o tipo de distúrbio analisado na seção 5.3.1, o sistema não diverge, mesmo para um tempo de retirada da falta pequeno ou grande. Os geradores saem do seu estado inicial e começam a oscilar em torno de um novo ponto de operação. Quando a potência mecânica de entrada se normaliza, as oscilações passam a ocorrer em torno do antigo ponto de equilíbrio;

* Para o segundo tipo de distúrbio, o sistema perde a estabilidade para qualquer tempo de retirada de falta superior a $t=0.213 \mathrm{~s}$. Para tempos antes disso, o sistema permanece estável;

* No terceiro tipo de distúrbio, o sistema diverge para um tempo de falta superior a 0,104 s e converge para tempos de falta inferiores. 


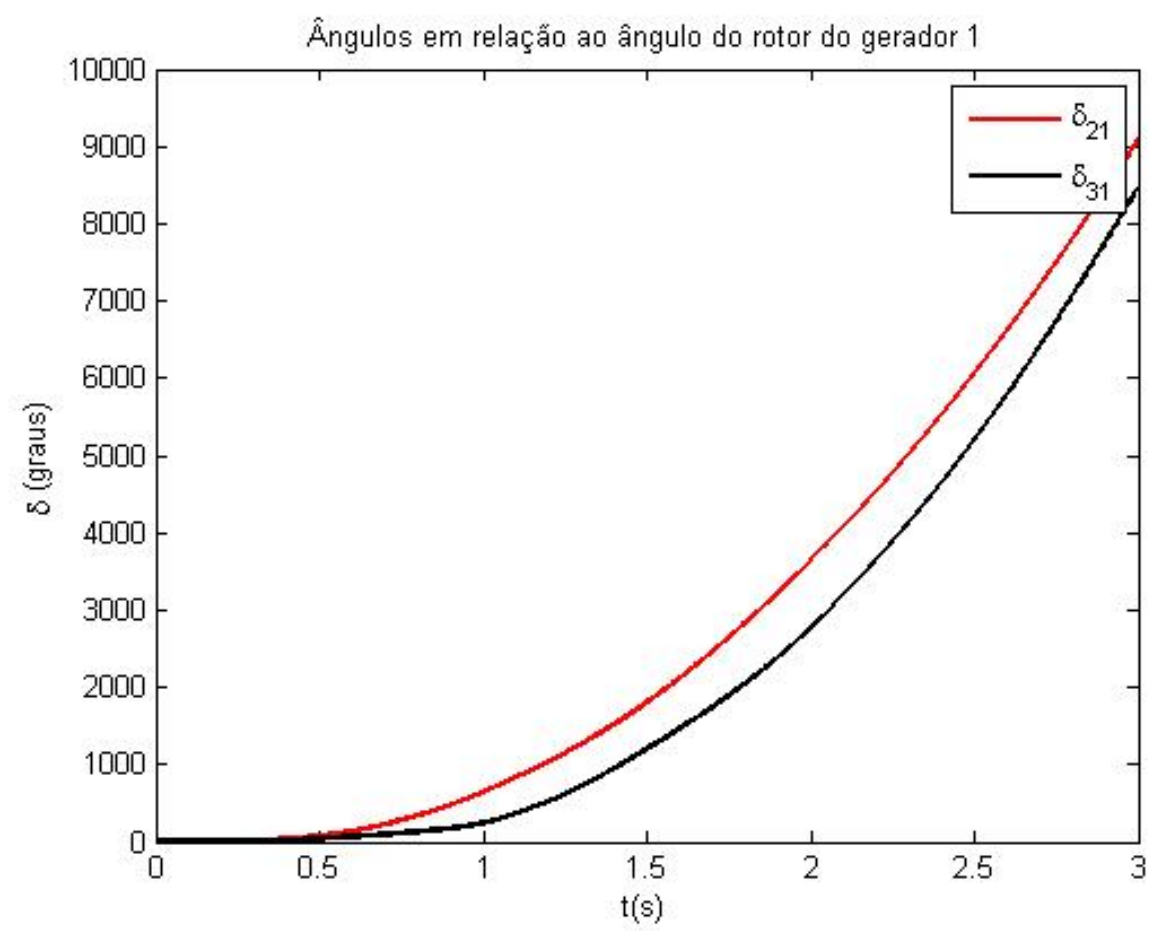

Figura 5.14: Resposta de $\delta$ a um curto na barra $7, t_{\text {falta }}=0,7 \mathrm{~s}$

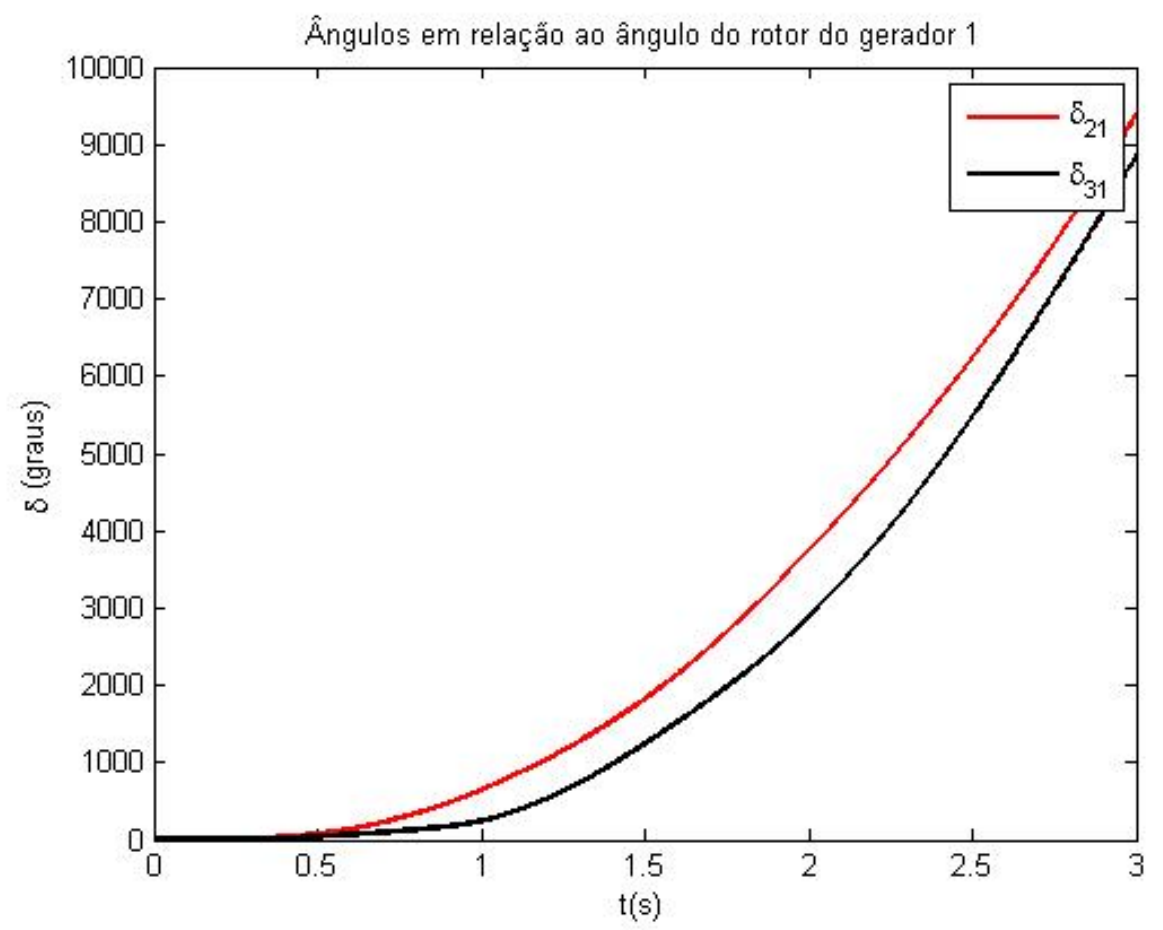

Figura 5.15: Defasagem Angular para um curto na barra 7 com retirada da linha 5-7, $t_{\text {falta }}=0,65 \mathrm{~s}$ 


\section{Capítulo 6 CONCLUSÕES}

\subsection{CONSIDERAÇÕES FINAIS}

Este trabalho apresentou uma contribuição no estudo da estabilidade transitória em sistemas elétricos de potência. Foi desenvolvido um programa capaz de realizar a análise da estabilidade transitória de sistemas elétricos de potência possibilitando assim realizar a simulação e estudo do comportamento transitório de máquinas síncronas quando o sistema é submetido a grandes perturbações. Neste programa é implementada a forma de análise por meio de um esquema de resolução simultânea dos sistemas de equações algébricas e diferenciais que representam os devidos sistemas elétricos a serem analisados.

Diversos métodos de integração foram abordados e implementados para a devida resolução das equações diferenciais, tornando-se necessário uma análise de cada um, verificando o seu desempenho em presença de descontinuidades, sua estabilidade numérica e seus erros relacionados à discretização do problema. No entanto, por apresentar melhores características quanto à estabilidade numérica quando exigido grandes esforços computacionais, foi dado um foco especial ao método Trapezoidal Implícito, sendo possível verificar sua eficiência nas diversas simulações realizadas.

Uma metodologia para a determinação das condições do sistema ao longo do tempo foi utilizada para conceber o programa. Tal metodologia se baseia fortemente no método de Newton-Raphson e em métodos de integração, onde, através de diversas iterações, se partisse de um valor estimado dos parâmetros do sistema e chegasse a valores mais próximos do que se deseja alcançar.

A partir do programa elaborado, realizaram-se estudos de caso apresentando resultados e simulações para diferentes modelos de geradores. Para o caso base, foram utilizados 
os métodos de integração de Euler, Runge-Kutta e Trapezoidal Implícito podendo visualizar o comportamento de cada um. Já para o caso de 9 barras foi utilizado apenas o método Trapezoidal Implícito. Apresentou-se também as vantagens e desvantagens de cada método, verificando resultados satisfatórios de acordo com os esperados.

Para uma melhor interação do usuário com o programa, foi desenvolvida uma interface gráfica para melhor manuseio da ferramenta, permitindo que o usuário através de elementos gráficos seja capaz de manipular de forma prática a inserção de parâmetros dos modelos de geradores levados em consideração neste documento.

\subsection{SUGESTÕES PARA TRABALHOS FUTUROS}

O tema abordado neste trabalho é de grande utilidade e não se limita ao que foi apresentado. Há vários tópicos que dão margem a trabalhos futuros, dentre eles, sugerese os seguintes estudos:

- Análise de sistemas de maior porte, utilizando uma modelagem mais completa de cargas;

- Abordagem de um número maior de modelos de geradores, aplicados a sistemas de tamanhos diversos;

- Inserção de dispositivos reguladores de velocidade e tensão;

- Comparação dos resultados das simulações com softwares do grupo Cepel e não apenas com a literatura.

- Reduzir o número de simplificações, como, por exemplo, considerando a resistência de armadura e a constante de amortecimento na equação swing, fazendo com que a análise se torne mais sofisticada. 


\section{Referências Bibliográficas}

[1] P. Kundur. Power System Control and Stability. McGraw-Hill, Inc., 1994.

[2] V. L. R. Ruggiero, M. A. G. e Lopes. Cálculo Numérico-Aspectos Teóricos e Computacionais. $2^{\mathrm{a}}$ edição, Makron books, 1998.

[3] W.D. Stevenson Júnior. Elementos de análise de sistemas de potência, $2^{a}$ edição. McGraw-Hill, Inc., São Paulo, 1986.

[4] B. Stott. Power System Dynamic Response Calculations. IEEE Proceeding. Vol. 67, n. 2, February 1979, p. 219-241., 1979.

[5] M. D. C. Pereira. Desenvolvimento de um objeto de aprendizagem para análise de sistemas de energia elétrica. Ilha Solteira, 2008. UNESP.

[6] R. C. Borges. Um algorítimo para sintonia de controladores robustos para amortecimento de modos intra-planta e sistemas de potência. Escola de Engenharia de São Carlos, 2009 ,.

[7] P. M. Anderson and A. A. Fouad. Power System Control and Stability. New York: IEEE Press, 1994.

[8] N. G. Alberto, L. F. C.; Bretas. Estabilidade Transitória em Sistemas Eletroenergéticos. EESC/USP, São Paulo, 1978.

[9] CEPEL. Manual do usuário do PacDyn. Centro de Pesquisas de Energia Elétrica, Rio de Janeiro, Brasil, 2002.

[10] I. M. de T. CAMARGO. Notas de aula da disciplina estabilidade de sistemas de potência. Universidade de Brasília, Brasília-DF, 2008 ,. Departamento de Engenharia. 
[11] Simões Costa A. e Silveira e Silva A. Controle e Estabilidade de Sistemas Elétricos de Potência. Notas de Aulas, UFSC, 2002.

[12] A. J. Monticelli. Fluxo de Carga em Redes de Energia Elétrica. Edgard Blücher LTDA, 1983.

[13] R. V. De Oliveira. Projeto de controladores de amortecimento para sistemas elétricos de potência. Escola de Engenharia de São Carlos da Universidade de São Paulo, 2006 ,. 


\section{Apêndice A RESULTADOS DAS SIMULAÇÕES}

Abaixo seguem os resultados da simulação para os métodos de Euler e Runge-Kutta $2^{\mathrm{a}}$ ordem e $4^{\mathrm{a}}$ ordem.

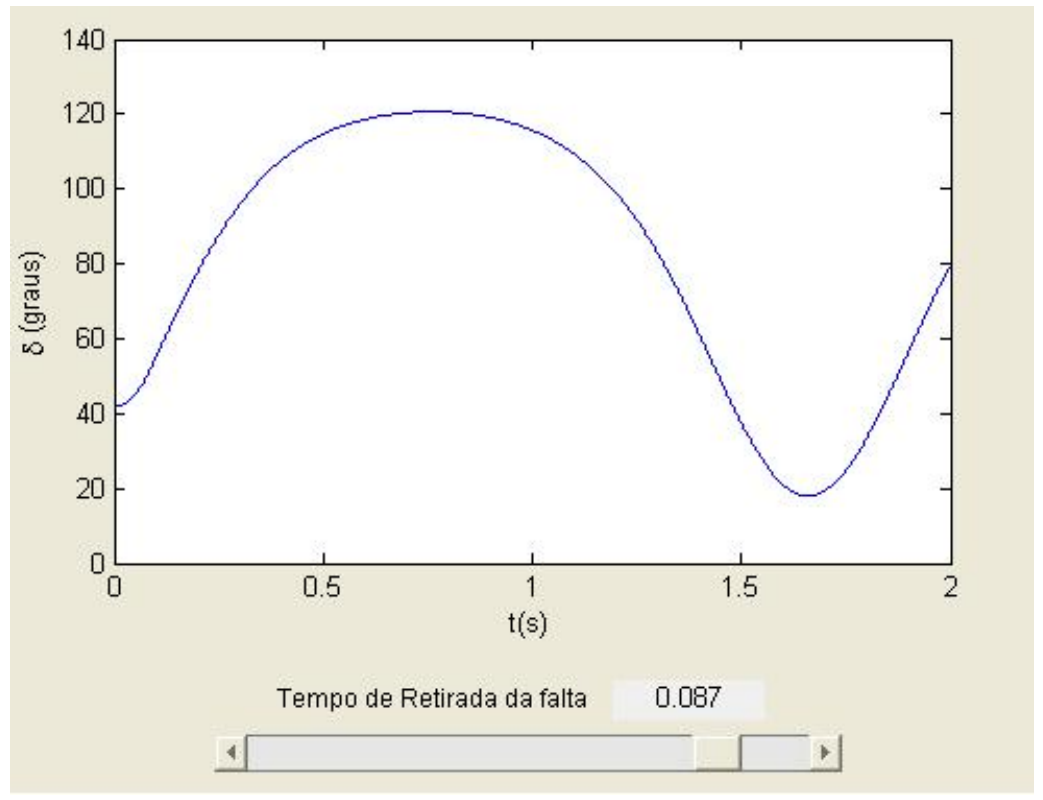

(a) Tempo máximo para estabilidade

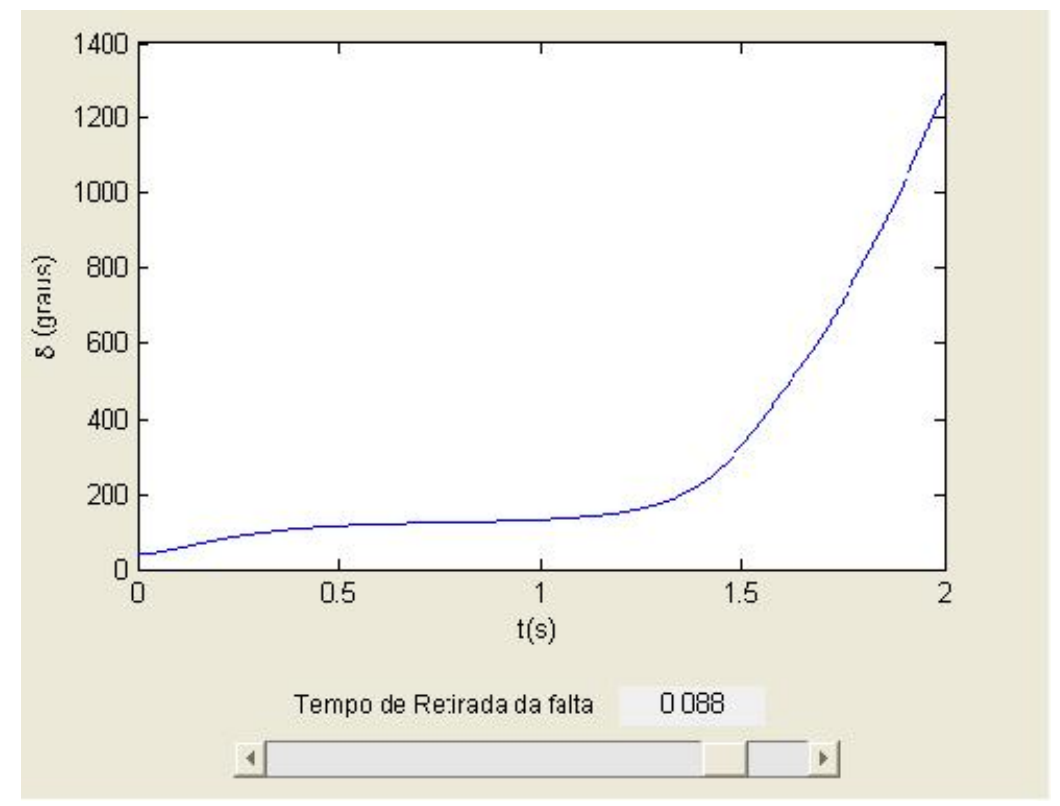

(b) Tempo mínimo para instabilidade

Figura A.1: Simulação: Método de Euler 


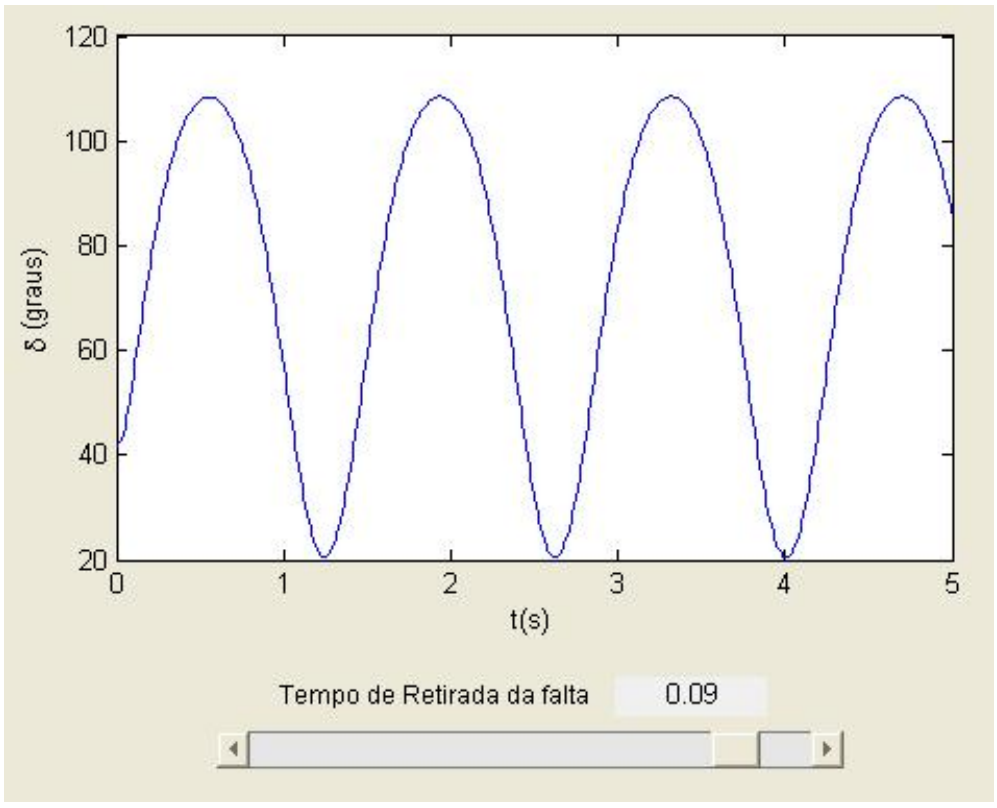

(a) Tempo máximo para estabilidade

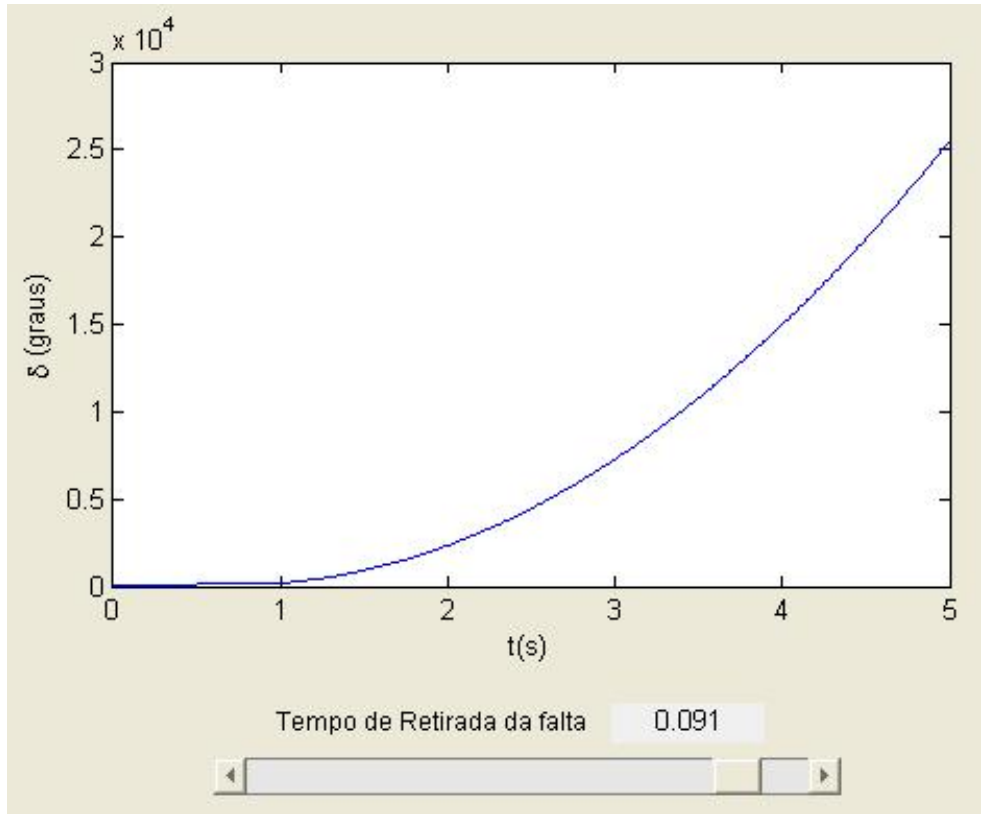

(b) Tempo mínimo para instabilidade

Figura A.2: Simulação: Método de Runge-Kutta $2^{\mathrm{a}}$ ordem 


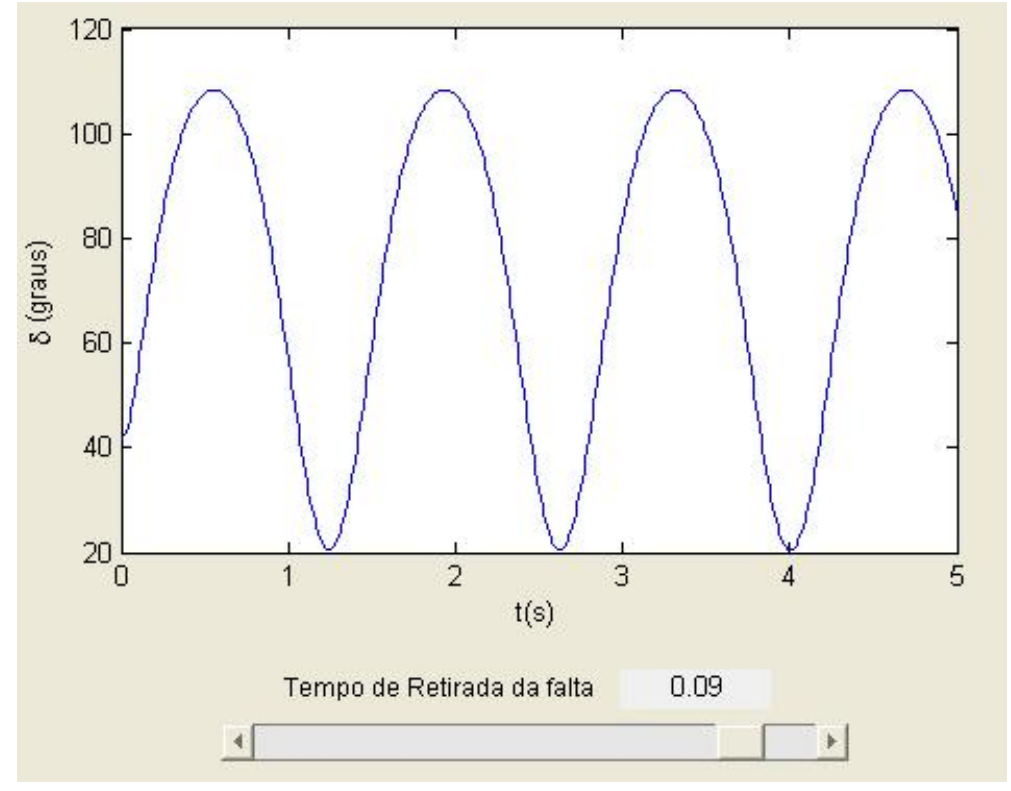

(a) Tempo máximo para estabilidade

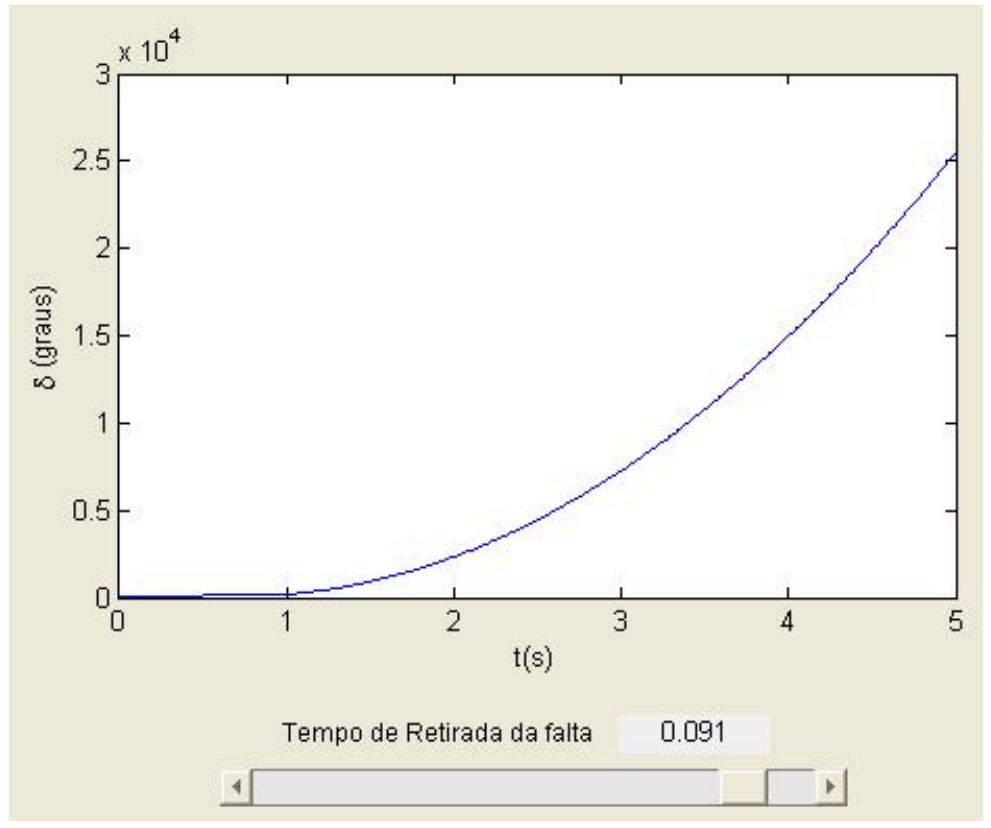

(b) Tempo mínimo para instabilidade

Figura A.3: Simulação: Método de Runge-Kutta $4^{\mathrm{a}}$ ordem

Abaixo segue os gráficos das simulações para o método Trapezoidal, modelos clássico, \#3, \#4 e \#5. 


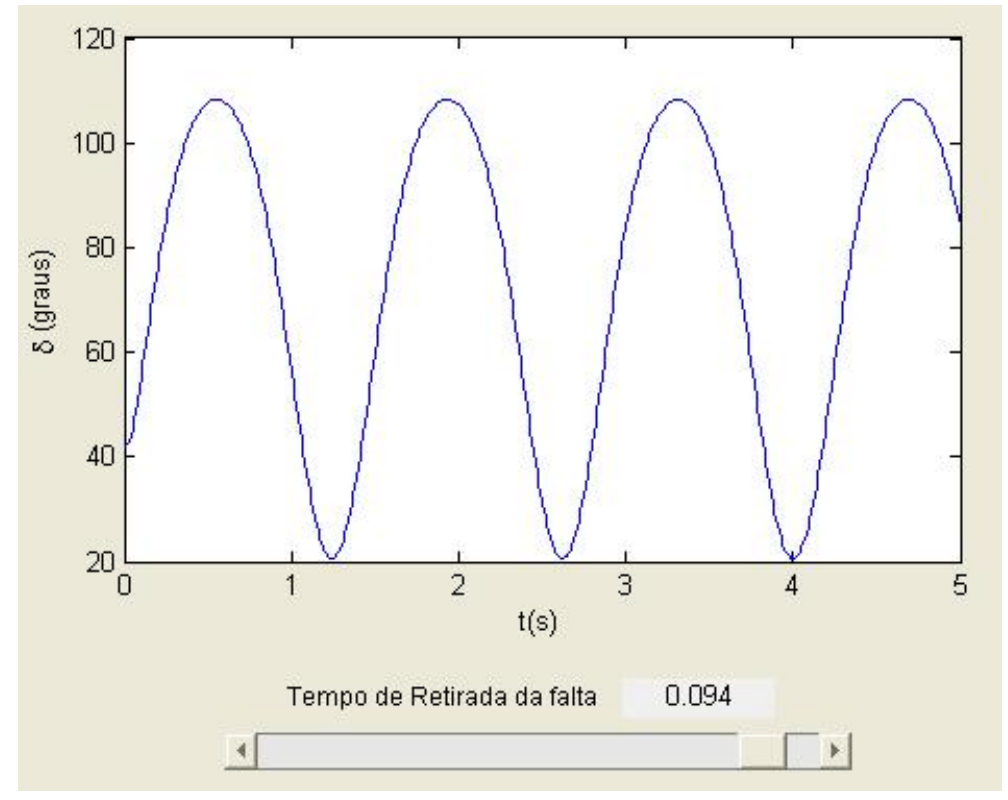

(a) Tempo máximo para estabilidade

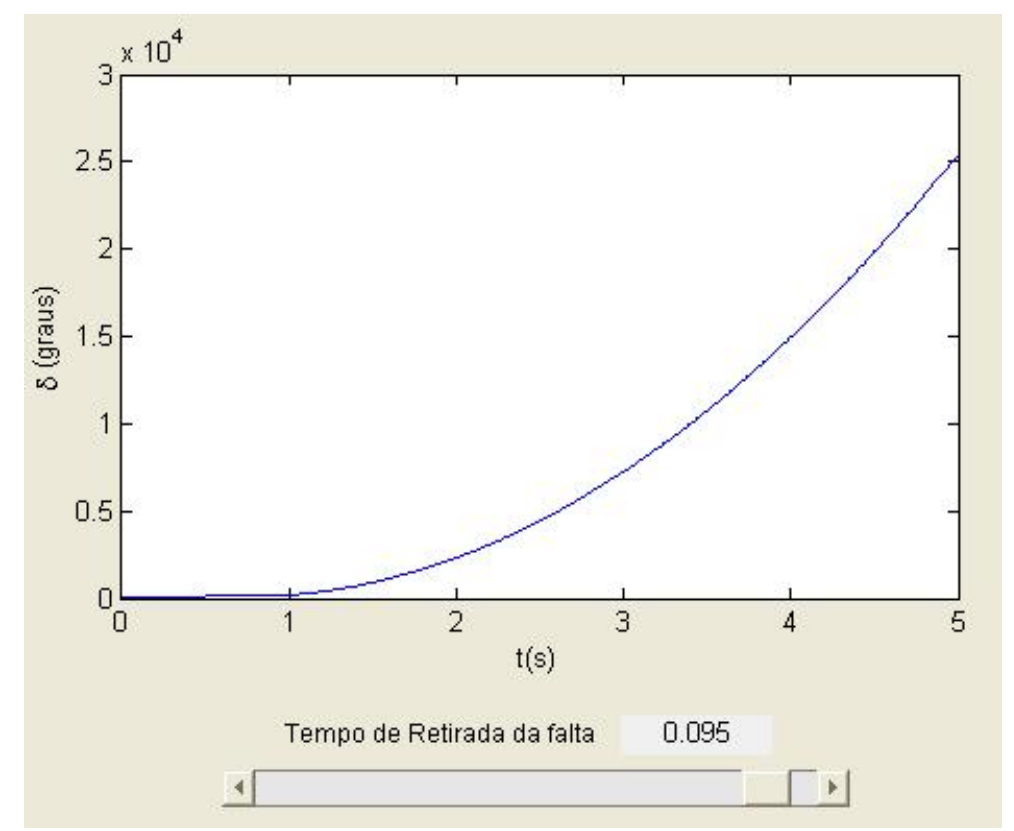

(b) Tempo mínimo para instabilidade

Figura A.4: Simulação: Modelo Clássico 


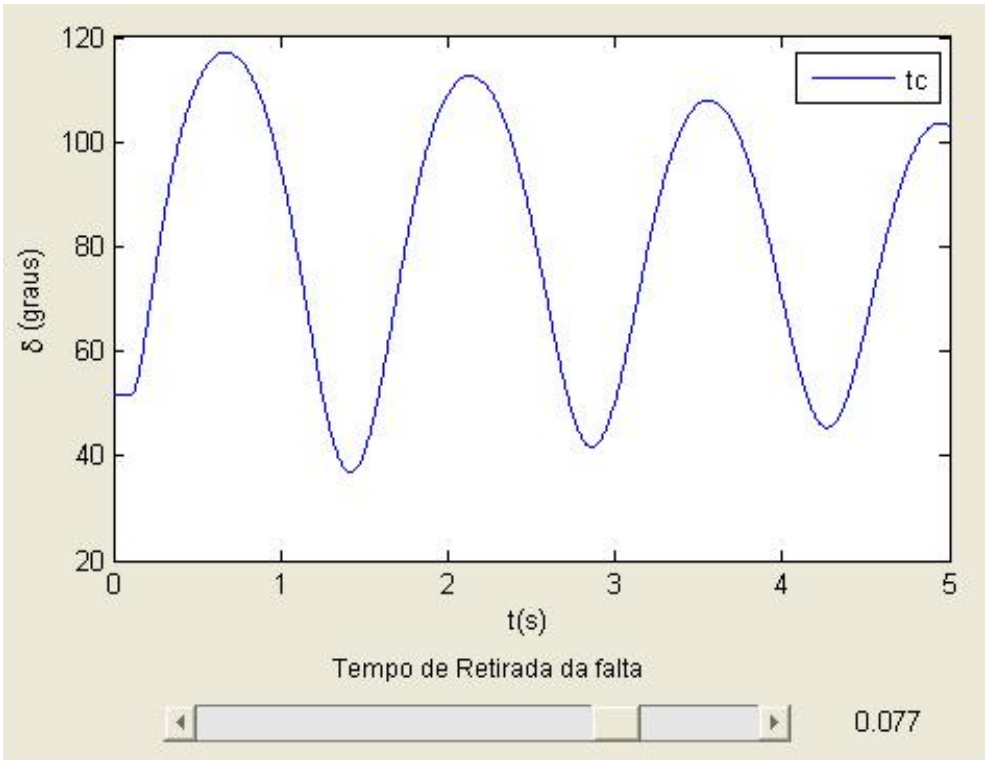

(a) Tempo máximo para estabilidade

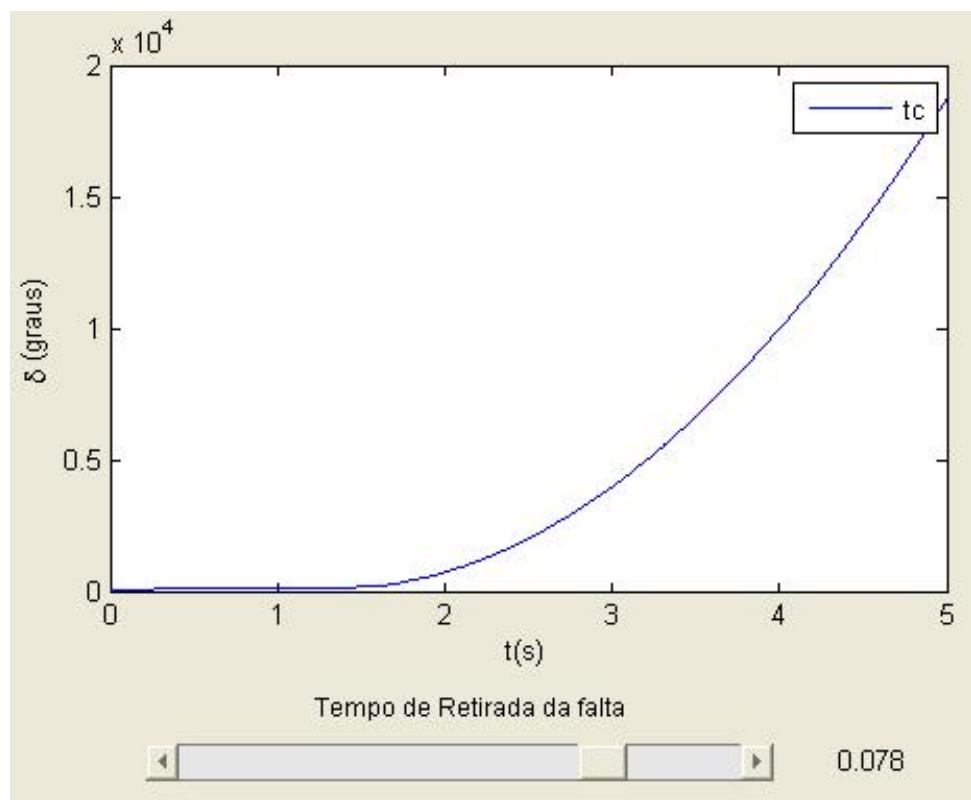

(b) Tempo mínimo para instabilidade

Figura A.5: Simulação: Modelo \#3 


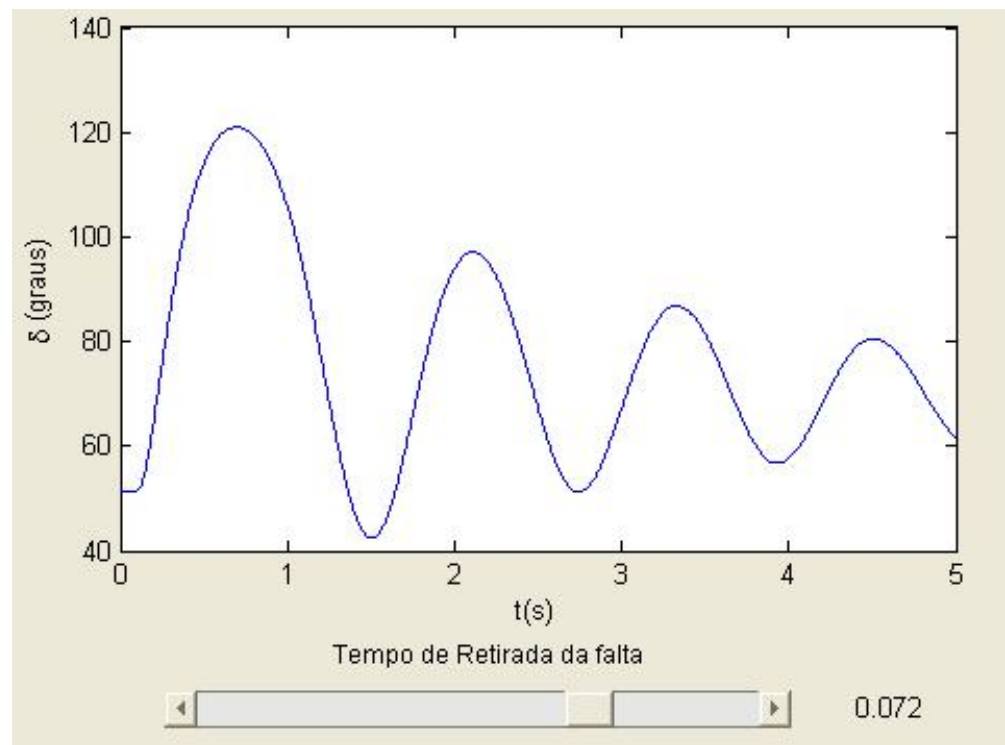

(a) Tempo máximo para estabilidade

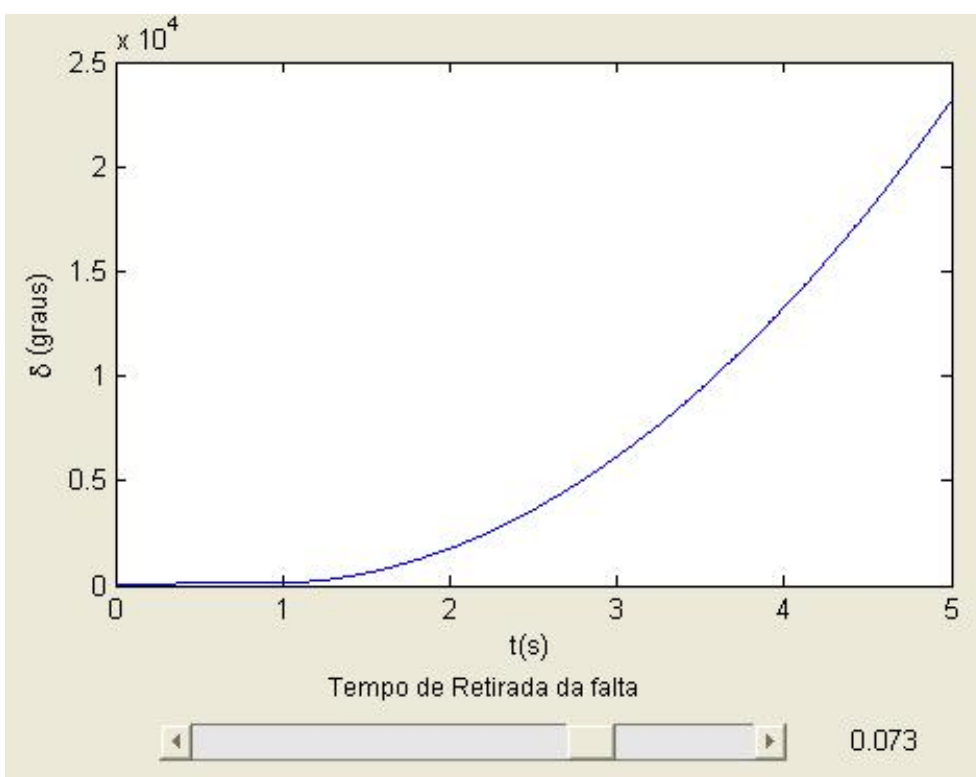

(b) Tempo mínimo para instabilidade

Figura A.6: Simulação: Modelo \#4 


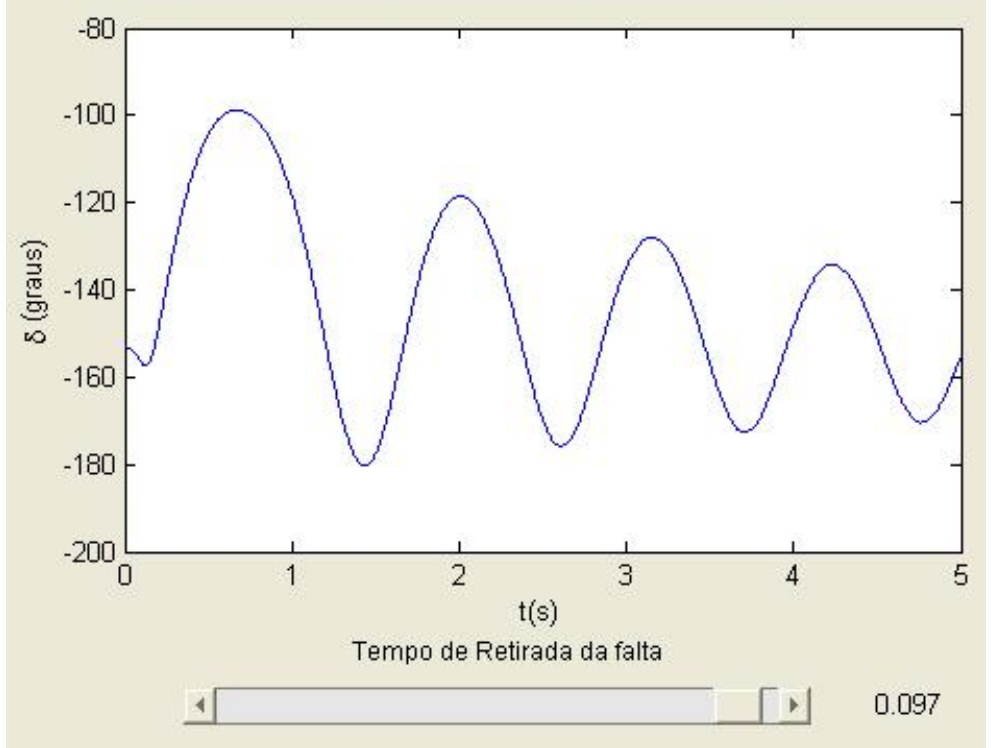

(a) Tempo máximo para estabilidade



(b) Tempo mínimo para instabilidade

Figura A.7: Simulação: Modelo \#5 